\title{
A Q-RUNG ORTHOPAIR FUZZY GLDS METHOD FOR INVESTMENT EVALUATION OF BE ANGEL CAPITAL IN CHINA
}

\author{
Huchang LIAO ${ }^{1}{ }^{1,2}$, Hongrun $\mathrm{ZHANG}^{1}$, Cheng ZHANG ${ }^{\left(\mathbb{D} 1^{*}\right.}$, Xingli WU1, \\ Abbas MARDANI ${ }^{3}$, Abdullah AL-BARAKATI ${ }^{2}$ \\ ${ }^{1}$ Business School, Sichuan University, Chengdu 610064, China \\ ${ }^{2}$ Faculty of Computing and Information Technology, King Abdulaziz University, \\ Jeddah 21589, Saudi Arabia \\ ${ }^{3}$ Azman Hashim International Business School, Universiti Teknologi Malaysia, \\ 81310 UTM, Johor, Malaysia
}

Received 08 February 2019; accepted 30 June 2019

\begin{abstract}
As a generalized form of both intuitionistic fuzzy set and Pythagorean fuzzy sets, the q-rung orthopair fuzzy set (q-ROFS) has strong ability to handle uncertain or imprecision decisionmaking problems. This paper aims to introduce a new multiple criteria decision making method based on the original gain and lost dominance score (GLDS) method for investment evaluation. To do so, we first propose a new distance measure of q-rung orthopair fuzzy numbers (q-ROFNs), which takes into account the hesitancy degree of q-ROFNs. Subsequently, two methods are developed to determine the weights of DMs and criteria, respectively. Next, the original GLDS method is improved from the aspects of dominance flows and order scores of alternatives to address the multiple criteria decision making problems with q-ROFS information. Finally, a case study concerning the investment evaluation of the $\mathrm{BE}$ angle capital is given to illustrate the applicability and superiority of the proposed method.
\end{abstract}

Keywords: investment evaluation, multiple criteria decision making, gained and lost dominance score method, q-rung orthopair fuzzy sets, distance measure, weight determination.

JEL Classification: C44, D70, D81, L83.

\section{Introduction}

Uncertainty is filled with our daily life. For instance, when a decision-maker (DM) evaluates a student's scientific research ability, he/she may give the judgment as "not bad". Obviously, such an evaluation is imprecise. How to deal with such imprecision is a problem researched by many scholars over the past decades (Atanassov, 1986; Yager, 2014; Liu \& Liao, 2017;

*Corresponding author. E-mail: z_zhangcheng_c@163.com

This is an Open Access article distributed under the terms of the Creative Commons Attribution License (http://creativecommons. org/licenses/by/4.0/), which permits unrestricted use, distribution, and reproduction in any medium, provided the original author and source are credited. 
Liu, Aiwu, Lukovac, \& Vukic, 2018a; Pamučar, Badi, Sanja, \& Obradović, 2018; Pamučar, Sremac, Stević, Ćirović, \& Tomić, 2019). As two effective extensions of Zadeh (1965)'s fuzzy set, Atanassov (1986) and Yager (2014) respectively proposed the intuitionistic fuzzy set (IFS) and Pythagorean fuzzy set (PFS) to represent the imprecise information by the membership function $\alpha$, non-membership function $\beta$ and hesitancy function $\gamma$ with the conditions: $0 \leq \alpha+\beta \leq 1$ for the IFS and $0 \leq \alpha^{2}+\beta^{2} \leq 1$ for the PFS. However, both of them fail to tackle some cases in real life. For example, suppose that a DM express his/her opinion in $(0.6,0.9)$, neither the IFS nor PFS can model this case because $0.6+0.9>0.1$ and $0.6^{2}+0.9^{2}>0.1$. In this regard, Yager (2017) proposed the concept of q-rung orthopair fuzzy set (q-ROFS), which also describes DMs' opinions from the aspects of membership function $\alpha$, non-membership $\beta$ and hesitancy functions $\gamma$, but the constraint was relaxed to $\alpha^{q}+\beta^{q}+\gamma^{q}=1(q \geq 1)$ rather than $\alpha+\beta+\gamma=1$ for the IFS or $\alpha^{2}+\beta^{2}+\gamma^{2}=1$ for the PFS. In this way, the above limitation can be overcome.

Since the q-ROFS was proposed, it has attracted increasing attention from scholars (Yager, 2017; Du, 2018a, 2018b; Gao, Liang, Shang, \& Xu, 2018; Joshi, Singh, Bhatt, \& Vaisla, 2018; Liu \& Wang, 2018, 2019; G. W. Wei, Gao, \& Y. Wei, 2018; Peng, Dai, \& Garg, 2018; Wang et al., 2019; P. D. Liu \& J. L. Liu, 2018; Liu, Chen \& Wang, 2018b. These achievements can be classified into different topics, such as information measures (Du, 2018a, 2018b), q-ROF function (Gao et al., 2018), interval-valued q-ROFS (Joshi et al., 2018) and q-ROF aggregation operators (Liu \& Wang, 2018, 2019; Wei et al., 2018; Peng et al., 2018; Wang et al., 2019; P. D. Liu \& J. L. Liu, 2018; Liu et al., 2018b, 2018). For example, Du (2018a, $2018 \mathrm{~b})$ studied the distance measures and correlation measures between q-ROFSs. Gao et al. (2018) proposed the q-ROF functions and then discussed their properties in depth, which contains the continuities, derivatives and differentials of the q-ROF functions. In addition, Joshi et al. (2018) proposed the interval-valued q-ROFS and then defined its basic operations and aggregation operators, respectively. Besides, a series of aggregation operators of q-ROFS have been studied in recent years. Yager (2017) introduced the concept of q-ROFS and then proposed the q-rung orthopair fuzzy (q-ROF) ordered weighted aggregation operator. Liu and Wang (2018) investigated the weighted averaging operator and weighted geometric operator of q-ROFSs. Wei et al. (2018) proposed several aggregation operators for generalized q-ROFSs, which contains the q-ROF generalized Heronian mean operator, q-ROF generalized weighted Heronian mean operator, q-ROF geometric Heronian mean operator, and q-ROF weighted geometric Heronian mean operator. Peng et al. (2018) defined a new score function of q-rung orthopair fuzzy number (q-ROFN) and then investigated the q-ROF weighted exponential aggregation operator. Moreover, some scholars also extended the classical operators to q-ROFS circumstance and proposed the q-ROF Archimedean Bonferroni mean operator (Liu \& Wang, 2019), q-ROF Maclaurin symmetric mean operator (P. D. Liu \& J. L. Liu, 2018), and q-ROF Bonferroni mean operator (P. D. Liu \& J. L. Liu, 2018; Liu et al., 2018a), respectively.

As we can see, there are few methods to solve multiple criteria decision making (MCDM) problems with q-ROF information. As usual, the MCDM methods can be classified into two types (Liao, Xu, Herrera-Viedma, \& Herrera, 2018b): utility value-based methods such as the TOPSIS, VIKOR, COPRAS, MABAC, and CODAS, and outranking methods such 
as the ELECTRE, PROMETHEE, and TODIM. Essentially, the TOPSIS, VIKOR, COPRAS, MABAC and CODAS need to choose a compromise solution, that is, the nearest alternative to the ideal solution. However, the TOPSIS method does not consider the relative importance of distances of each alternative to the positive ideal solution and negative ideal solution. The VIKOR method calculates the utility values of alternatives from the perspectives of group utility and individual regret value respectively, but ignores the subordination of alternatives. The same limitation exists in the CODAS, MABAC and COPRAS methods. The ELECTRE method suffers from complex computation and time-consuming because it derives the consistency and inconsistency indexes according to the subdivision relations between alternatives (including dominance relation, indifference relation and incomparable relation). Although the PROMETHEE method can calculate the positive (negative) dominant flows of alternatives, it fails to describe the accurate relationships between alternatives under imprecise environment. Moreover, the standardization process is neglected in the TODIM method and the selected alternative may have poor performance under some criteria because the individual regret values are not taken into account.

Based on the gained and lost dominance connections between alternatives, $\mathrm{Wu}$ and Liao (2019) originally proposed the gain and lost dominance score (GLDS) method to solve cognitive complex MCDM problems. The GLDS method is a new dominance-based method. The principle of the GLDS method is to compare any an alternative $A_{i}$ with all the other alternatives $A_{v}(v=1,2, \cdots, m ; v \neq i)$ under a criterion, and then aggregate the gained/lost dominance scores of $A_{i}$ to get its overall gained/lost dominance score. After that, two rankings of alternatives are obtained according to the gained dominance scores and lost dominance scores. Finally, a comprehensive ranking of alternatives is determined by an aggregation function. Comparing with other existing MCDM methods, the GLDS method has the following advantages (Wu \& Liao, 2019):

- The solution obtained from the GLDS method is the closest one to the ideal solution;

- The normalization process in the GLDS method can tackle different types of criteria, while such a process is always ignored in other dominance-based methods such as the TODIM method (Zhang, Xu, \& Liao, 2019) and PROMETHEE method (Liao et al., 2018a);

- The GLDS method takes into account the "group utility" and "individual regret" simultaneously, and therefore the derived solution is more acceptable for most DMs.

However, there are also some limitations in the initial GLDS method. Firstly, in the original GLDS method, the overall lost dominance score only retains the largest value but ignores all the other values. This assumption would fit some MCDM problems in which the DMs are risk-averse, but it fails to handle the case in which the DMs are risk-preferred or even preference dependence. Subsequently, the original GLDS method is limited to handle the MCDM problems with probability linguistic information (Liao, Jiang, Z. S. Xu, J. P. Xu, \& Herrera, 2017). Although the hesitant fuzzy linguistic GLDS method (Fu, Wu, Liao, \& Herrera, 2018) was proposed recently, it can only be used to handle the qualitative MCDM problems, but cannot tackle the problems with q-ROF information. Thus, this paper aims to improve the GLDS method to overcome these two limitations.

To do so, methods to derive the weights of DMs and criteria are respectively investigated according to the newly proposed distance measure of q-ROFNs. After that, we improve the 
initial GLDS method by integrating the order scores of alternatives with a new aggregation function. To summary, the contributions of this paper can be highlighted as follows:

- We propose a new distance measure of q-ROFNs in which the membership degree, non-membership degree and hesitancy degree are considered, simultaneously.

- A new method to determine the weights of DMs is investigated by the improved TOPSIS method. Meanwhile, a goal programming-based method is developed to derive the weights of criteria.

- A new concept called the order score of an alternative is defined. Then, a q-ROFGLDS method is proposed in which a new aggregation function is introduced to integrate the dominance flows and the order scores of alternatives to obtain the ranking of alternatives.

- We apply the q-ROF-GLDS method to address a case study concerning the investment evaluation for BE angle capital. The validity of the method is verified by some comparative analyses.

The remainder of this paper is constructed as follows: In Section 1, knowledge of the q-ROFS and the initial GLDS method is recalled, respectively. A new distance measure of q-ROFNs is proposed in Section 2. Two methods are applied in Section 3 to determine the weights of DMs and criteria, respectively. In Section 4, we improve the initial GLDS method within the context of q-ROFSs and then propose the q-ROF-GLDS method. A case study related to the investment evaluation of the BE angle capital is presented in Section 5 to demonstrate the applicability and superiority of the proposed MCDM method. The study ends with some conclusions in the final section.

\section{The q-rung orthopair fuzzy set}

In this section, concepts and operations related to q-ROFSs are recalled for the facility of future presentation.

As a generalized form of both the IFS and PFS, the q-ROFS provides DMs more freedom to express their opinions on the membership and non-membership grades. Let $X=\left\{x_{1}, x_{2}, \cdots, x_{n}\right\}$ be a universe of discourse. A q-ROFS $A$ in $X$ is mathematically defined as (Yager, 2017)

$$
A=\left\{<x,\left(\alpha_{A}(x), \beta_{A}(x)\right)>\mid x \in X\right\},
$$

where $\alpha_{A}(x): X \rightarrow[0,1]$ is the membership function and $\beta_{A}(x): X \rightarrow[0,1]$ is the nonmembership function, satisfying $\alpha_{A}(x) \in[0,1], \beta_{A}(x) \in[0,1], 0 \leq\left(\alpha_{A}(x)\right)^{q}+\left(\beta_{A}(x)\right)^{q} \leq 1$ $(q \geq 1)$. For any $x,\left(\alpha_{A}(x), \beta_{A}(x)\right)_{q}$ is called a $q$-ROFN. The hesitancy degree of a q-ROFS is defined as

$$
\gamma_{A}(A)=\left(1-\left(\alpha_{A}(x)\right)^{q}-\left(\beta_{A}(x)\right)^{q}\right)^{1 / q}
$$

For a q-ROFN $a=\left(\alpha_{a}, \beta_{a}\right)_{q}$, the score function and accuracy function can be defined as (Liu \& Wang, 2018):

$$
s(a)=\left(\alpha_{a}\right)^{q}-\left(\beta_{a}\right)^{q}, h(a)=\left(\alpha_{a}\right)^{q}+\left(\beta_{a}\right)^{q}, \text { for } q \geq 1 .
$$


On this basis, Liu and Wang (2018) proposed a method to compare q-ROFNs. For any two q-ROFNs $a_{1}=\left(\alpha_{1}, \beta_{1}\right)_{q}$ and $a_{2}=\left(\alpha_{2}, \beta_{2}\right)_{q}$, (1) if $s\left(a_{1}\right)>s\left(a_{2}\right)$, then $a_{1}>a_{2}$; (2) if $s\left(a_{1}\right)=s\left(a_{2}\right)$, then if $h\left(a_{1}\right)>h\left(a_{2}\right), a_{1}>a_{2}$, and if $h\left(a_{1}\right)=h\left(a_{2}\right), a_{1}=a_{2}$.

Let $a=\left(\alpha_{a}, \beta_{a}\right)_{q}, b=\left(\alpha_{b}, \beta_{b}\right)_{q}$ be two q-ROFNs. Liu and Wang (2018) gave the operations of q-ROFNs as follows:

(1) $a \oplus b=\left(\left(\alpha_{a}^{q}+\alpha_{b}^{q}-\alpha_{a}^{q} \alpha_{b}^{q}\right)^{1 / q}, \beta_{a} \beta_{b}\right)$;

(2) $a \otimes b=\left(\beta_{a} \beta_{b},\left(\alpha_{a}^{q}+\alpha_{b}^{q}-\alpha_{a}^{q} \alpha_{b}^{q}\right)^{1 / q}\right)$;

(3) $\varepsilon a=\left(\left(1-\left(1-\alpha_{a}^{q}\right)^{\varepsilon}\right)^{1 / q}, \beta_{a}^{q}\right)$;

(4) $a^{\varepsilon}=\left(\beta_{a}^{q},\left(1-\left(1-\alpha_{a}^{q}\right)^{\varepsilon}\right)^{1 / q}\right)$.

For a collection of q-ROFNs $a_{j}(j=1,2, \ldots, n)$ with $\omega=\left(\omega_{1}, \omega_{2}, \cdots, \omega_{n}\right)^{T}$ being their weight vector such that $\omega_{j} \in[0,1]$ and $\sum_{j=1}^{n} \omega_{j}=1$, Liu and Wang (2018) proposed a qrung orthopair fuzzy weighted averaging operator (q-ROFWA) as:

$$
q-\operatorname{ROFWA} A_{\omega}\left(a_{1}, a_{2}, \cdots, a_{n}\right)=\bigoplus_{j=1}^{n}\left(\omega_{j} a_{j}\right)=\left\langle\left(1-\prod_{j=1}^{n}\left(1-a_{j}^{q}\right)^{\omega_{j}}\right)^{1 / q}, \prod_{j=1}^{n} \beta_{j}^{\omega_{j}}\right\rangle .
$$

\section{A novel distance measure of the q-ROFNs}

In this subsection, a novel Euclidean distance measure between q-ROFNs is proposed, and its properties are further investigated in detail.

Let $a_{1}=\left(\alpha_{1}, \beta_{1}\right)$ and $a_{2}=\left(\alpha_{2}, \beta_{2}\right)$ be two q-ROFNs. The Euclidean distance between $a_{1}$ and $a_{2}$ can be defined as:

$$
\begin{aligned}
& d\left(a_{1}, a_{2}\right)= \\
& \left\{\begin{array}{l}
\frac{1}{q_{*}} \cdot \sqrt{\frac{1}{2}\left(\left(\left(\alpha_{1}\right)^{q_{*}}-\left(\alpha_{2}\right)^{q_{*}}\right)^{2}+\left(\left(\beta_{1}\right)^{q_{*}}-\left(\beta_{2}\right)^{q_{*}}\right)^{2}+\left(\left(\gamma_{1}\right)^{q_{*}}-\left(\gamma_{2}\right)^{q_{*}}\right)^{2}\right)}, \text { if }\left(\alpha_{1}\right)^{q_{1}}=\left(\alpha_{2}\right)^{q_{2}},\left(\beta_{1}\right)^{q_{1}}=\left(\beta_{2}\right)^{q_{2}}, q_{1} \neq q_{2}, \\
\frac{\left|q_{2}-q_{1}\right|+1}{q_{*}} \cdot \sqrt{\frac{1}{2}\left(\left(\left(\alpha_{1}\right)^{q_{1}}-\left(\alpha_{2}\right)^{q_{2}}\right)^{2}+\left(\left(\beta_{1}\right)^{q_{1}}-\left(\beta_{2}\right)^{q_{2}}\right)^{2}+\left(\left(\gamma_{1}\right)^{q_{1}}-\left(\gamma_{2}\right)^{q_{2}}\right)^{2}\right)}, \text { otherwise }
\end{array},\right.
\end{aligned}
$$

where $q_{1}, q_{2}$ and $q_{\star}$ are three integers with $q_{1}, q_{2} \in[1,+\infty)$ and $q_{*}=\max \left\{q_{1}, q_{2}\right\}$.

Theorem 1 reveals the properties of the proposed Euclidean distance of q-ROFNs.

Theorem 1. Let $a_{1}=\left(\alpha_{1}, \beta_{1}\right), a_{2}=\left(\alpha_{2}, \beta_{2}\right)$ and $a_{3}=\left(\alpha_{3}, \beta_{3}\right)$ be three q-ROFNs. Then, (1) $d\left(a_{1}, a_{2}\right)=d\left(a_{2}, a_{1}\right)$; (2) $d\left(a_{1}, a_{2}\right)=0$ if and only if $a_{1}=a_{2}$; (3) $0 \leq d\left(a_{1}, a_{2}\right) \leq 1$; (4) If $a_{1} \leq a_{2} \leq a_{3}$ and $q_{1}=q_{2}=q_{3}$, then $d\left(a_{1}, a_{2}\right) \leq d\left(a_{1}, a_{3}\right)$ and $d\left(a_{2}, a_{3}\right) \leq d\left(a_{1}, a_{3}\right)$.

The proof of Theorem 1 can be found in the Appendix.

In what follows, several examples regarding q-ROFNs, PFNs and IFNs are provided to demonstrate the applicability and superiority of the proposed Euclidean distance of q-ROFNs compared with some existing formulas.

Example 1. Let $a_{1}=(0.60,0.80), a_{2}=(0.36,0.64), a_{3}=(0.70,0.80), a_{4}=(0.90,0.80)$ and $a_{5}=(0.60,0.50)$ be five q-ROFNs. Then, both Eq. (5) and Du's method shown as $D_{E}(A, B)$ in Ref. (Du, 2018a) are respectively used to calculate the distances between them. The calculation results are shown in Table 1. 
Table 1. Calculation results of the Euclidean distances between q-ROFNs

\begin{tabular}{|l|c|c|c|c|c|c|c|c|c|c|}
\hline Method & $d\left(a_{1}, a_{2}\right)$ & $d\left(a_{1}, a_{3}\right)$ & $d\left(a_{1}, a_{4}\right)$ & $d\left(a_{1}, a_{5}\right)$ & $d\left(a_{2}, a_{3}\right)$ & $d\left(a_{2}, a_{4}\right)$ & $d\left(a_{2}, a_{5}\right)$ & $d\left(a_{3}, a_{4}\right)$ & $d\left(a_{3}, a_{5}\right)$ & $d\left(a_{4}, a_{5}\right)$ \\
\hline $\begin{array}{l}\text { Du } \\
(2018 \mathrm{a})\end{array}$ & 0.1638 & 0.0639 & 0.3626 & 0.2096 & 0.1934 & 0.4416 & 0.0740 & 0.2987 & 0.2191 & 0.4188 \\
\hline $\begin{array}{l}\text { This } \\
\text { paper }\end{array}$ & 0.1152 & 0.0915 & 0.2244 & 0.1950 & 0.1373 & 0.2805 & 0.3900 & 0.1336 & 0.1693 & 0.2221 \\
\hline
\end{tabular}

Example 2. Let $a_{1}=(0.90,0.30), a_{2}=(0.70,0.50), a_{3}=(0.50,0.80), a_{4}=(0.10,0.80)$ and $a_{5}=(0.70,0.40)$ be five q-ROFNs. Then, Eq. (5), Eq. (3.3) in Zhang and Xu (2014) and Eq. (13) in Li and Zeng (2018) are respectively used to calculate the distances between them. The calculation results are shown in Table 2.

Table 2. Calculation results of the Euclidean distances between PFNs

\begin{tabular}{|l|l|l|l|l|l|l|l|l|l|l|}
\hline Method & $d\left(a_{1}, a_{2}\right)$ & $d\left(a_{1}, a_{3}\right)$ & $d\left(a_{1}, a_{4}\right)$ & $d\left(a_{1}, a_{5}\right)$ & $d\left(a_{2}, a_{3}\right)$ & $d\left(a_{2}, a_{4}\right)$ & $d\left(a_{2}, a_{5}\right)$ & $d\left(a_{3}, a_{4}\right)$ & $d\left(a_{3}, a_{5}\right)$ & $d\left(a_{4}, a_{5}\right)$ \\
\hline $\begin{array}{l}\text { Zhang } \\
\text { and Xu } \\
(2014)\end{array}$ & 0.3200 & 0.5600 & 0.8000 & 0.3200 & 0.3900 & 0.4800 & 0.0900 & 0.2400 & 0.4800 & 0.4800 \\
\hline $\begin{array}{l}\text { Li and } \\
\text { Zeng } \\
(2018)\end{array}$ & 0.1760 & 0.3884 & 0.5964 & 0.1467 & 0.2231 & 0.4270 & 0.0653 & 0.2526 & 0.2817 & 0.4660 \\
\hline $\begin{array}{l}\text { This } \\
\text { paper }\end{array}$ & 0.1386 & 0.2775 & 0.7100 & 0.1457 & 0.1704 & 0.4900 & 0.0450 & 0.1552 & 0.2078 & 0.5587 \\
\hline
\end{tabular}

Example 3. Let $a_{1}=(0.60,0.40), a_{2}=(0.36,0.64), a_{3}=(0.70,0.20), a_{4}=(0.30,0.50)$ and $a_{5}=(0.40,0.50)$ be five IFNs. Then, Eq. (5) and Eq. (61) in Szmidt and Kacprzyk (2000) are respectively employed to calculate the distances between them. The calculation results are shown in Table 3.

Table 3. Calculation results of the Euclidean distances between IFNs

\begin{tabular}{|l|l|l|l|l|l|l|l|l|l|l|}
\hline Method & $d\left(a_{1}, a_{2}\right)$ & $d\left(a_{1}, a_{3}\right)$ & $d\left(a_{1}, a_{4}\right)$ & $d\left(a_{1}, a_{5}\right)$ & $d\left(a_{2}, a_{3}\right)$ & $d\left(a_{2}, a_{4}\right)$ & $d\left(a_{2}, a_{5}\right)$ & $d\left(a_{3}, a_{4}\right)$ & $d\left(a_{3}, a_{5}\right)$ & $d\left(a_{4}, a_{5}\right)$ \\
\hline $\begin{array}{l}\text { Szmidt } \\
\text { and } \\
\text { Kacprzyk } \\
(2000)\end{array}$ & 0.2400 & 0.1732 & 0.2646 & 0.1732 & 0.3995 & 0.1778 & 0.1249 & 0.3606 & 0.3000 & 0.1000 \\
\hline $\begin{array}{l}\text { This } \\
\text { paper }\end{array}$ & 0.2400 & 0.1732 & 0.2646 & 0.1732 & 0.3995 & 0.1778 & 0.1249 & 0.3606 & 0.3000 & 0.1000 \\
\hline
\end{tabular}

From Example 1, we find that there exists differences between the results calculated by $\mathrm{Du}$ (2018a)'s method and the proposed method. According to these two methods, we obtain different ranking results, which are $d\left(a_{2}, a_{4}\right)>d\left(a_{4}, a_{5}\right)>d\left(a_{1}, a_{4}\right)>d\left(a_{3}, a_{4}\right)>d\left(a_{3}, a_{5}\right)>$ $d\left(a_{1}, a_{5}\right)>d\left(a_{2}, a_{3}\right)>d\left(a_{1}, a_{2}\right)>d\left(a_{2}, a_{5}\right)>d\left(a_{1}, a_{3}\right)$ by Du's method and $d\left(a_{2}, a_{5}\right)>$ $d\left(a_{2}, a_{4}\right)>d\left(a_{1}, a_{4}\right)>d\left(a_{4}, a_{5}\right)>d\left(a_{1}, a_{5}\right)>d\left(a_{3}, a_{5}\right)>d\left(a_{2}, a_{3}\right)>d\left(a_{3}, a_{4}\right)>d\left(a_{1}, a_{2}\right)>$ $d\left(a_{1}, a_{3}\right)$ by the proposed method. In particular, using the proposed method, the values of $d\left(a_{1}, a_{3}\right)$ and $d\left(a_{2}, a_{5}\right)$ are 0.0915 and 0.3900 , which are different from the results obtained by Du's method shown as 0.0639 and 0.0740 . When applying the proposed method, $d\left(a_{2}, a_{5}\right)$ 
obtains the maximum value; however, $d\left(a_{2}, a_{4}\right)$ is the maximum one corresponding to Du's method. The main reason for this is that we consider the hesitancy degrees of q-ROFNs in the proposed distance measure. Moreover, we know that the ability to model DMs' opinions increases with the value of coefficient $q$ increases. In this regard, the value of coefficient $q$ should also be considered in measuring the deviation between q-ROFNs. Unfortunately, both the hesitancy degree and the value of coefficient $q$ were not considered in Du (2018a)'s method, and therefore the obtained results are questionable.

From Example 2, we know that $d\left(a_{1}, a_{4}\right)$ and $d\left(a_{2}, a_{5}\right)$ are, respectively, the maximum value and minimum value among all distance values. If we use Zhang and Xu (2014)'s method to calculate the distance between PFNs, then we have $d\left(a_{2}, a_{4}\right)=d\left(a_{3}, a_{5}\right)=d\left(a_{4}, a_{5}\right)$ and $d\left(a_{1}, a_{2}\right)=d\left(a_{2}, a_{3}\right)$. It reveals that Zhang and $\mathrm{Xu}$ (2014)'s method cannot accurately measure the difference between PFNs. Almost the same results can be obtained using Li and Zeng (2018)'s method and the proposed method, that is, $d\left(a_{1}, a_{4}\right)>d\left(a_{4}, a_{5}\right)>d\left(a_{2}, a_{4}\right)>$ $d\left(a_{1}, a_{3}\right)>d\left(a_{3}, a_{5}\right)>d\left(a_{3}, a_{4}\right)>d\left(a_{2}, a_{3}\right)>d\left(a_{1}, a_{2}\right)>d\left(a_{1}, a_{5}\right)>d\left(a_{2}, a_{5}\right)$ for the former and $d\left(a_{1}, a_{4}\right)>d\left(a_{4}, a_{5}\right)>d\left(a_{2}, a_{4}\right)>d\left(a_{1}, a_{3}\right)>d\left(a_{3}, a_{5}\right)>d\left(a_{2}, a_{3}\right)>d\left(a_{3}, a_{4}\right)>$ $d\left(a_{1}, a_{5}\right)>d\left(a_{1}, a_{2}\right)>d\left(a_{2}, a_{5}\right)$ for the latter. It should be note that Li and Zeng (2018)'s method is time-consuming because extra parameter including the strength of $a$ and its strength direction are needed to be determined in advance.

From Example 3, we can see that the same results are obtained by Szmidt and Kacprzyk (2000)'s method and the proposed method. Obviously, Eq. (5) is degraded to Eq. (61) in Szmidt and Kacprzyk (2000) if the given values are IFNs. Thus, as a general form of Szmidt and Kacprzyk (2000)'s method, the proposed method has wider applications and can be used to measure the difference between IFNs, PFNs or q-ROFNs.

Compared with the existing methods (Szmidt \& Kacprzyk, 2000; Zhang \& Xu, 2014; Du, 2018), the proposed distance measure for q-ROFNs has the following advantages: (1) it has wider application fields, which contains IFNs, PFNs, and q-ROFNs; (2) all the parameters including membership degree, non-membership degree and hesitancy degree are considered in the proposed formula, and therefore the obtained result is convincing; (3) the proposed formula is time-saving compared with Li and Zeng (2018)'s method.

\section{New weight-determining methods for DMs and criteria}

In this section, two novel methods are investigated to derive the weights of DMs and criteria, respectively.

\subsection{A method to determine the weights of DMs}

For a multi-expert MCDM problem which contains a collection of alternatives $A_{i}(i=1$, $2, \ldots, m)$ and a set of criteria $c_{j}(j=1,2, \ldots, n)$, assume that $t$ DMs are invited to assess the alternatives and then express their opinions in q-ROFNs. Let the weight vector of the DMs be $\lambda=\left(\lambda_{1}, \lambda_{2}, \cdots, \lambda_{k}\right)^{T}$, and the weight vector of the criteria be $w=\left(w_{1}, w_{2}, \cdots, w_{j}\right)^{T}$, respectively, satisfying $\lambda_{k}, w_{j} \geq 0, \sum_{k=1}^{t} \lambda_{k}=1$ and $\sum_{j=1}^{m} w_{j}=1$. All evaluations provided by the DMs 
are stored in q-ROF decision matrices, shown as follows:

$$
\begin{aligned}
& D^{(k)}=\left(d_{i j}^{(k)}\right)_{m \times n}=\left(\alpha_{i j}^{(k)}, \beta_{i j}^{(k)}\right)_{m \times n}=A_{i}\left(\begin{array}{cccccc}
c_{1} & \cdots & c_{j} & \cdots & c_{n} \\
\vdots & A_{1}\left(\alpha_{11}^{(k)}, \beta_{11}^{(k)}\right) & \cdots & \left(\alpha_{1 j}^{(k)}, \beta_{1 j}^{(k)}\right) & \cdots & \left(\alpha_{1 n}^{(k)}, \beta_{1 n}^{(k)}\right) \\
\vdots & \ddots & \vdots & \ddots & \vdots \\
A_{m}\left(\alpha_{i 1}^{(k)}, \beta_{i 1}^{(k)}\right) & \cdots & \left(\alpha_{i j}^{(k)}, \beta_{i j}^{(k)}\right) & \cdots & \left(\alpha_{i n}^{(k)}, \beta_{i n}^{(k)}\right) \\
\vdots & \ddots & \vdots & \ddots & \vdots \\
\left(\alpha_{m 1}^{(k)}, \beta_{i 1}^{(k)}\right) & \cdots & \left(\alpha_{m j}^{(k)}, \beta_{m j}^{(k)}\right) & \cdots & \left(\alpha_{m n}^{(k)}, \beta_{m n}^{(k)}\right)
\end{array}\right), \\
& k=1,2, \cdots, t .
\end{aligned}
$$

In this subsection, we investigate a new distance measure between q-ROFSs. After that, based on the positive ideal solution (PIS), negative ideal solution (NIS) and relative closeness formula, we propose an improved q-ROF TOPSIS method to derive the weights of DMs.

Firstly, we need to normalize the decision matrix $D^{(k)}$. Here, we use the following equation to obtain the dimensionless evaluations:

$$
d_{i j}^{N(k)}=\left(\alpha_{i j}^{N(k)}, \beta_{i j}^{N(k)}\right)=\left\{\begin{array}{ll}
\left(\alpha_{i j}^{(k)}, \beta_{i j}^{(k)}\right), & \text { for benefit criteria } \\
\left(\beta_{i j}^{(k)}, \alpha_{i j}^{(k)}\right), & \text { for cost criteria }
\end{array} .\right.
$$

The optimal solution should be closest to the PIS and farthest from the NIS. However, in actual multi-expert MCDM problems, there always does not exist the PIS since different DMs may have distinct preferences on alternatives. Thus, it is hard to find the PIS which is accepted by all DMs. In this case, we take the mean values of DMs' evaluations as the q-ROF PIS, that is

$$
P I S_{i j}^{*}=\left(\alpha_{i j}^{*}, \beta_{i j}^{*}\right),
$$

where $\alpha_{i j}^{*}=\frac{1}{t} \sum_{k=1}^{t} \alpha_{i j}^{(k)}$ and $\beta_{i j}^{*}=\frac{1}{t} \sum_{k=1}^{t} \beta_{i j}^{(k)}$, for all $i=1,2, \ldots, m, j=1,2, \ldots, n$.

Based on Eq. (8), the q-ROF PIS decision matrix is determined as

$$
P I S=\left(\begin{array}{ccccc}
\left(\alpha_{11}^{*}, \beta_{11}^{*}\right) & \ldots & \left(\alpha_{1 j}^{*}, \beta_{1 j}^{*}\right) & \ldots & \left(\alpha_{1 n}^{*}, \beta_{1 n}^{*}\right) \\
\vdots & \ddots & \vdots & \ddots & \vdots \\
\left(\alpha_{i 1}^{*}, \beta_{i 1}^{*}\right) & \ldots & \left(\alpha_{i j}^{*}, \beta_{i j}^{*}\right) & \ldots & \left(\alpha_{i n}^{*}, \beta_{i n}^{*}\right) \\
\vdots & \ddots & \vdots & \ddots & \vdots \\
\left(\alpha_{m 1}^{*}, \beta_{m 1}^{*}\right) & \cdots & \left(\alpha_{m j}^{*}, \beta_{m j}^{*}\right) & \cdots & \left(\alpha_{m n}^{*}, \beta_{m n}^{*}\right)
\end{array}\right) .
$$

We further discuss the q-ROF NIS from two aspects, including the left q-ROF NIS and the right q-ROF NIS. The q-ROF NIS, which is deemed as the worst solution, should be farthest from the q-ROF PIS. In this sense, we introduce the q-ROF NIS from two aspects, namely, the left q-ROF NIS NIS ${ }^{l}$ and the right q-ROF NIS NIS :

$$
\begin{aligned}
& N I S_{i j}^{l}=\left(\alpha_{i j}^{l-}, \beta_{i j}^{l-}\right), \text { for } i=1,2, \ldots, m, j=1,2, \ldots, n ; \\
& N I S_{i j}^{r}=\left(\alpha_{i j}^{r-}, \beta_{i j}^{r-}\right), \text { for } i=1,2, \ldots, m, j=1,2, \ldots, n,
\end{aligned}
$$


where $N I S_{i j}^{l}=\min _{k}\left\{s\left(\alpha_{i j}^{(k)}, \beta_{i j}^{(k)}\right)\right\}, s\left(\alpha_{i j}^{l-}, \beta_{i j}^{l-}\right) \leq s\left(\alpha_{i j}^{(k)}, \beta_{i j}^{(k)}\right), N I S_{i j}^{r}=\max _{k}\left\{s\left(\alpha_{i j}^{(k)}, \beta_{i j}^{(k)}\right)\right\}$ and $s\left(\alpha_{i j}^{r-}, \beta_{i j}^{r-}\right) \geq s\left(\alpha_{i j}^{k}, \beta_{i j}^{k}\right)$ for $k=1,2, \cdots, t . s\left(\alpha_{i j}^{(k)}, \beta_{i j}^{(k)}\right)$ denotes the score value derived by Eq. (3).

Based on Eqs (10) and (11), the left q-ROF NIS decision matrix NIS ${ }^{l}$ and the right q-ROF NIS decision matrix NIS ${ }^{r}$ are, respectively, determined as:

$$
\begin{gathered}
N I S^{l}=\left(\begin{array}{ccccc}
\left(\alpha_{11}^{l-}, \beta_{11}^{l-}\right) & \ldots & \left(\alpha_{1 j}^{l-}, \beta_{1 j}^{l-}\right) & \ldots & \left(\alpha_{1 n}^{l-}, \beta_{1 n}^{l-}\right) \\
\vdots & \ddots & \vdots & \ddots & \vdots \\
\left(\alpha_{i 1}^{l-}, \beta_{i 1}^{l-}\right) & \ldots & \left(\alpha_{i j}^{l-}, \beta_{i j}^{l-}\right) & \ldots & \left(\alpha_{i n}^{l-}, \beta_{i n}^{l-}\right) \\
\vdots & \ddots & \vdots & \ddots & \vdots \\
\left(\alpha_{m 1}^{l-}, \beta_{m 1}^{l-}\right) & \ldots & \left(\alpha_{m j}^{l-}, \beta_{m j}^{l-}\right) & \ldots & \left(\alpha_{m n}^{l-}, \beta_{m n}^{l-}\right)
\end{array}\right) ; \\
N I S^{r}=\left(\begin{array}{ccccc}
\left(\alpha_{11}^{r-}, \beta_{11}^{r-}\right) & \ldots & \left(\alpha_{1 j}^{r-}, \beta_{1 j}^{r-}\right) & \ldots & \left(\alpha_{1 n}^{r-}, \beta_{1 n}^{r-}\right) \\
\vdots & \ddots & \vdots & \ddots & \vdots \\
\left(\alpha_{i 1}^{r-}, \beta_{i 1}^{r-}\right) & \cdots & \left(\alpha_{i j}^{r-}, \beta_{i j}^{r-}\right) & \cdots & \left(\alpha_{i n}^{r-}, \beta_{i n}^{r-}\right) \\
\vdots & \ddots & \vdots & \ddots & \vdots \\
\left(\alpha_{m 1}^{r-}, \beta_{m 1}^{r-}\right) & \cdots & \left(\alpha_{m j}^{r-}, \beta_{m j}^{r-}\right) & \cdots & \left(\alpha_{m n}^{r-}, \beta_{m n}^{r-}\right.
\end{array}\right) .
\end{gathered}
$$

Remark 1. NIS ${ }^{l}$ and NIS ${ }^{r}$ shown as Eqs. (12) and (13) are, respectively, expressed as the PIS and NIS in the existing TOPSIS method (Zhang et al., 2019). The reason why we choose them as the q-ROF NIS is that $\left(\alpha_{i j}^{(k)}, \beta_{i j}^{(k)}\right)$, which is either close or far from PIS $S_{i j}^{*}$, is viewed as the non-optimal solution. In particular, if $\left(\alpha_{i j}^{(k)}, \beta_{i j}^{(k)}\right)$ has the biggest distance from $P I S_{i j}^{*}$ and satisfies $s\left(\alpha_{i j}^{l-}, \beta_{i j}^{l-}\right) \leq s\left(\alpha_{i j}^{(k)}, \beta_{i j}^{(k)}\right)$, then it is regarded as the left q-ROF NIS, i.e., NIS ; otherwise, if $\left(\alpha_{i j}^{(k)}, \beta_{i j}^{(k)}\right)$ has the biggest distance from $P I S_{i j}^{*}$ and satisfies $s\left(\alpha_{i j}^{r-}, \beta_{i j}^{r-}\right) \geq s\left(\alpha_{i j}^{k}, \beta_{i j}^{k}\right)$, then it is regarded as the right q-ROF NIS, i.e., NIS .

Once PIS, NIS ${ }^{l}$ and NIS ${ }^{r}$ are determined, we shall calculate the distances of them to the $k$ th DM's q-ROF decision matrix $D^{N(k)}(k=1,2, \cdots, t)$. Based on Eqs (14), (15) and (16), we can obtain the distances from PIS, NIS, NIS $S^{r}$ to $D^{N(k)}$ as

$$
\begin{aligned}
& d\left(\alpha_{i j}^{*}, \alpha_{i j}^{N(k)}\right)=\left\{\begin{array}{l}
\frac{1}{q_{*}} \cdot \sqrt{\left.\frac{1}{2}\left(\left(\alpha_{i j}^{*}\right)^{q_{*}}-\left(\alpha_{i j}^{N(k)}\right)^{q_{*}}\right)^{2}+\left(\left(\beta_{i j}^{*}\right)^{q_{*}}-\left(\beta_{i j}^{N(k)}\right)^{q_{*}}\right)^{2}+\left(\left(\gamma_{i j}^{*}\right)^{q_{*}}-\left(\gamma_{i j}^{N(k)}\right)^{q_{*}}\right)^{2}\right),}, \text { if }\left(\alpha_{i j}^{*}\right)^{q_{1}}=\left(\alpha_{i j}^{N(k)}\right)^{q_{2}},\left(\beta_{i j}^{*}\right)^{q_{1}}=\left(\beta_{i j}^{N(k)}\right)^{q_{2}}, q_{1} \neq q_{2} \\
\frac{\left|q_{2}-q_{1}\right|+1}{q_{*}} \cdot \sqrt{\left.\frac{1}{2}\left(\left(\alpha_{i j}^{*}\right)^{q_{1}}-\left(\alpha_{i j}^{N(k)}\right)^{q_{2}}\right)^{2}+\left(\left(\beta_{i j}^{*}\right)^{q_{1}}-\left(\beta_{i j}^{N(k)}\right)^{q_{2}}\right)^{2}+\left(\left(\gamma_{i j}^{*}\right)^{q_{1}}-\left(\gamma_{i j}^{N(k)}\right)^{q_{2}}\right)^{2}\right)},
\end{array}\right.
\end{aligned}
$$

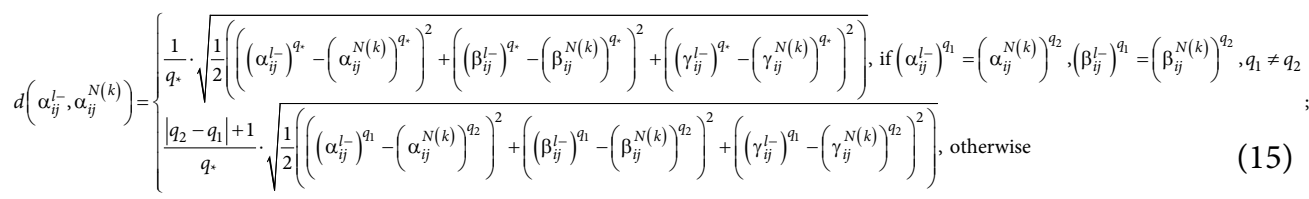




$$
d\left(\alpha_{i j}^{l+}, \alpha_{i j}^{N(k)}\right)=\left\{\begin{array}{l}
\frac{1}{q_{*}} \cdot \sqrt{\left.\frac{1}{2}\left(\left(\alpha_{i j}^{l+}\right)^{q_{*}}-\left(\alpha_{i j}^{N(k)}\right)^{q_{*}}\right)^{2}+\left(\left(\beta_{i j}^{l+}\right)^{q_{*}}-\left(\beta_{i j}^{N(k)}\right)^{q_{*}}\right)^{2}+\left(\left(\gamma_{i j}^{l+}\right)^{q_{*}}-\left(\gamma_{i j}^{N(k)}\right)^{q_{*}}\right)^{2}\right)}, \text { if }\left(\alpha_{i j}^{l_{i j}}\right)^{q_{1}}=\left(\alpha_{i j}^{N(k)}\right)^{q_{2}},\left(\beta_{i j}^{l+l}\right)^{q_{1}}=\left(\beta_{i j}^{N(k)}\right)^{q_{2}}, q_{1} \neq q_{2} \\
\frac{\left|q_{2}-q_{1}\right|+1}{q_{*}} \cdot \sqrt{\left.\frac{1}{2}\left(\left(\alpha_{i j}^{l+q^{l}}\right)^{q_{1}}-\left(\alpha_{i j}^{N(k)}\right)^{q_{2}}\right)^{2}+\left(\left(\beta_{i j}^{l+}\right)^{q_{1}}-\left(\beta_{i j}^{N(k)}\right)^{q_{2}}\right)^{2}+\left(\left(\gamma_{i j}^{l+}\right)^{q_{1}}-\left(\gamma_{i j}^{N(k)}\right)^{q_{2}}\right)^{2}\right)},
\end{array},\right.
$$

where $q_{1}, q_{2}$ are integers with $q_{1}, q_{2} \in[1,+\infty)$. In addition, for Eqs (14)-(16), $\left(\alpha_{i j}^{*}\right)^{q_{1}}+\left(\beta_{i j}^{*}\right)^{q_{1}} \leq 1$ $\left(\left(\alpha_{i j}^{N(k)}\right)^{q_{1}}+\left(\beta_{i j}^{N(k)}\right)^{q_{1}} \leq 1\right)$ and $\left(\alpha_{i j}^{*}\right)^{q_{1}-1}+\left(\beta_{i j}^{*}\right)^{q_{1}-1}>1 \quad\left(\left(\alpha_{i j}^{N(k)}\right)^{q_{1}-1}+\left(\beta_{i j}^{N(k)}\right)^{q_{1}-1}>1\right)$ hold for all $i=1,2, \ldots, m$ and $j=1,2, \cdots, n$.

According to Eqs (17)-(19), the distances $d\left(P I S, D^{N(k)}\right), d\left(N I S^{l}, D^{N(k)}\right)$ and $d\left(N I S^{r}, D^{N(k)}\right)$ are, respectively, calculated by

$$
\begin{aligned}
& d\left(P I S, D^{N(k)}\right)=\frac{1}{m n} \sum_{i=1}^{m} \sum_{j=1}^{n} d\left(\alpha_{i j}^{*}, \alpha_{i j}^{N(k)}\right) ; \\
& d\left(N I S^{l}, D^{N(k)}\right)=\frac{1}{m n} \sum_{i=1}^{m} \sum_{j=1}^{n} d\left(\alpha_{i j}^{l-}, \alpha_{i j}^{N(k)}\right) ; \\
& d\left(N I S^{r}, D^{N(k)}\right)=\frac{1}{m n} \sum_{i=1}^{m} \sum_{j=1}^{n} d\left(\alpha_{i j}^{l+}, \alpha_{i j}^{N(k)}\right) .
\end{aligned}
$$

We further derive the relative closeness $R C^{(k)}$ of the $k$ th DM by

$$
\begin{aligned}
R C^{(k)}= & \frac{\max _{l, r}\left\{d\left(N I S^{l}, D^{N(k)}\right) / d\left(N I S^{(k)}, D^{N(k)}\right), d\left(N I S^{r}, D^{N(k)}\right) / d\left(N I S^{l}, D^{N(k)}\right)\right\}}{\max _{k}\left\{\max _{l, r}\left\{d\left(N I S^{l}, D^{N(k)}\right) / d\left(N I S^{r}, D^{N(k)}\right), d\left(N I S^{r}, D^{N(k)}\right) / d\left(N I S^{l}, D^{N(k)}\right)\right\}\right\}}- \\
& \frac{d\left(P I S, D^{N(k)}\right)}{\min _{k}\left\{d\left(P I S, D^{N(k)}\right)\right\}} .
\end{aligned}
$$

The smaller the value of $R C^{(k)}$ is, the lower importance of the $k$ th DM should be, and vice versa.

Remark 2. Different from the relative closeness formula in the original TOPSIS method, in this paper, we use Eq. (29) to compute the relative closeness value of each DM. The key principle of Eq. (20) is to find out the optimal solution which has the shortest distance from PIS and farthest distances from NIS ${ }^{l}$ and NIS $r$, simultaneously.

On this basis, the weights of the DMs can be calculated by

$\lambda_{k}=0.8 / t+0.2 *\left(R C^{(k)} / \sum_{k=1}^{t} R C^{(k)}\right), k=1,2, \cdots, t$

such that $\lambda_{k} \geq 0, \sum_{k=1}^{t} \lambda_{k}=1$. 
Next, we use the aggregation operator shown as Eq. (4) to aggregate DMs' decision matrices, $D^{N(k)}=\left(d_{i j}^{N(k)}\right)_{m \times n}(k=1,2, \cdots, t)$, to obtain the collective one:

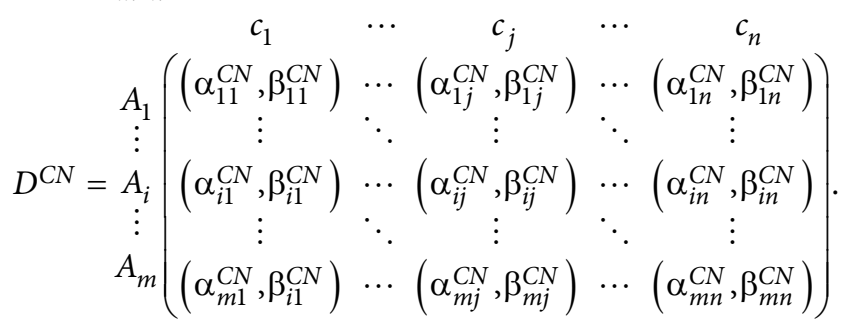

\subsection{A method to determine the weights of criteria}

In this subsection, based on the maximizing deviation method (Wang, 1997), models are constructed to determine the weights of criteria.

As we know, the weights of criteria play a crucial role in solving MCDM problems. Unreasonable weights would lead to a questionable or even counter-intuitive decision results in real life. In most existing MCDM methods with q-ROF information (Peng et al., 2018), the weights of criteria are predefined. It makes the decision results be of subjectivity. To address this issue, we introduce several goal programming models to determine the weights of criteria.

For criterion $c_{j}$, the deviation of alternative $A_{i}$ to all the other alternatives $A_{v}$ $(v \neq i, v=1,2, \cdots, m)$ can be measured by

$$
f_{i j}(w)=w_{j} \sum_{i=1}^{m} d^{2}\left(\left(\alpha_{i j}^{C N}, \beta_{i j}^{C N}\right),\left(\alpha_{v j}^{C N}, \beta_{v j}^{C N}\right)\right) .
$$

Using Eq. (5), Eq. (23) can be rewritten as

$$
\begin{aligned}
& f_{j}(w)= \\
& w_{j} \sum_{v=1}^{m} \sum_{i=1}^{m}\left\{\begin{array}{l}
\frac{\left|q_{2}-q_{1}\right|+1}{q_{*}} \cdot \sqrt{\left(\left(\alpha_{i j}^{C N}\right)^{q_{1}}-\left(\alpha_{v j}^{C N}\right)^{q_{2}}\right)^{2}+\left(\left(\beta_{i j}^{C N}\right)^{q_{1}}-\left(\beta_{v j}^{C N}\right)^{q_{2}}\right)^{2}+\left(\left(\alpha_{i j}^{C N}\right)^{q_{1}}-\left(\alpha_{v j}^{C N}\right)^{q_{2}}\right)\left(\left(\beta_{i j}^{C N}\right)^{q_{1}}-\left(\beta_{v j}^{C N}\right)^{q_{2}}\right)}, \text { otherwise } \\
\sqrt{\left.\left(\alpha_{i j}^{C N}\right)^{q_{1}}-\left(\alpha_{v j}^{C N}\right)^{q_{2}}\right)^{2}+\left(\left(\beta_{i j}^{C N}\right)^{q_{1}}-\left(\beta_{v j}^{C N}\right)^{q_{2}}\right)^{2}+\left(\left(\alpha_{i j}^{C N}\right)^{q_{1}}-\left(\alpha_{v j}^{C N}\right)^{q_{2}}\right)\left(\left(\beta_{i j}^{C N}\right)^{q_{1}}-\left(\beta_{v j}^{C N}\right)^{q_{2}}\right)}, \text { if }\left(\alpha_{1}\right)^{q_{1}}=\left(\alpha_{2}\right)^{q_{2}},\left(\beta_{1}\right)^{q_{1}}=\left(\beta_{2}\right)^{q_{2}}, q_{1} \neq q_{2}
\end{array},\right.
\end{aligned}
$$

where $q_{1}, q_{2}$ are two integers with $q_{1}, q_{2} \in[1,+\infty)$. In addition, in Eq. (24), $\left(\alpha_{i j}^{C N}\right)^{q_{1}}+$ $\left(\beta_{i j}^{C N}\right)^{q_{1}} \leq 1$ and $\left(\alpha_{i j}^{C N}\right)^{q_{1}-1}+\left(\beta_{i j}^{C N}\right)^{q_{1}-1}>1$ hold for all $i=1,2, \ldots, m, j=1,2, \ldots, n$.

The key point to address MCDM problems is to find out an optimal alternative with good performances under all criteria. Meanwhile, in actual life, there often exist several alternatives which have approximate or equal performances on a certain criterion. Thus, it is unrealistic to assign all criteria with the same importance. By contrast, the larger the performance differences among the alternatives on a criterion is, the higher the importance of this criterion should be. Therefore, we should assign the weights of criteria which can maximize the deviations of all criteria. In this regard, we can construct the following goal programming model: 


\section{Model 1}

$$
\begin{aligned}
\max F(w) & =\sum_{j=1}^{m} w_{j} \sum_{v=1}^{m} \sum_{i=1}^{m} d^{2}\left(\left(\alpha_{i j}^{C N}, \beta_{i j}^{C N}\right),\left(\alpha_{v j}^{C N}, \beta_{v j}^{C N}\right)\right) \\
\text { s.t. } & \left\{\begin{array}{l}
0 \leq w_{j} \leq 1, j=1,2, \cdots, n \\
\sum_{j=1}^{n} w_{j}^{2}=1 \\
q_{1}, q_{2} \in[1,+\infty)
\end{array}\right.
\end{aligned}
$$

where $\left(\alpha_{i j}^{C N}\right)^{q_{1}}+\left(\beta_{i j}^{C N}\right)^{q_{1}} \leq 1$ and $\left(\alpha_{i j}^{C N}\right)^{q_{1}-1}+\left(\beta_{i j}^{C N}\right)^{q_{1}-1}>1$ hold for all $i=1,2, \ldots, m$ and $j=1,2, \ldots, n$.

Solving Model 1 by the Lagrange multiplier method, the optimal weights of criteria can be determined as

$$
w_{j}=\frac{\sum_{v=1}^{m} \sum_{i=1}^{m} d^{2}\left(\left(\alpha_{i j}^{C N}, \beta_{i j}^{C N}\right),\left(\alpha_{v j}^{C N}, \beta_{v j}^{C N}\right)\right)}{\sqrt{\sum_{j=1}^{m}\left(\sum_{v=1}^{m} \sum_{i=1}^{m} d^{2}\left(\left(\alpha_{i j}^{C N}, \beta_{i j}^{C N}\right),\left(\alpha_{v j}^{C N}, \beta_{v j}^{C N}\right)\right)\right)^{2}}}, j=1,2, \ldots, n .
$$

By maximizing the distances among different alternatives under the criteria, we can obtain the optimal weights of criteria based on the above goal programming model. If there exists larger deviation among alternatives under a certain criterion, then a higher weight should be assigned to this criterion.

Except the case that the weights of criteria are completely unknown, the situation that the weights of criteria are partially known is also common in many MCDM problems. In this case, similar to Model 1, we shall construct the following single goal programming model to calculate the weights of criteria:

\section{Model 2}

$$
\begin{aligned}
\max F(w) & =\sum_{j=1}^{m} w_{j} \sum_{v=1}^{m} \sum_{i=1}^{m} d^{2}\left(\left(\alpha_{i j}^{C N}, \beta_{i j}^{C N}\right),\left(\alpha_{v j}^{C N}, \beta_{v j}^{C N}\right)\right) \\
\text { s.t.: } & \left\{\begin{array}{l}
w \in \theta \\
0 \leq w_{j} \leq 1, j=1,2, \cdots, n \\
\sum_{j=1}^{n} w_{j}=1 \\
q_{1}, q_{2} \in[1,+\infty)
\end{array}\right.
\end{aligned}
$$

where $\theta$ denotes the known information of criteria weights. In addition, it should be noted that the normalized constraint of weights in Model 2 is $\sum_{j=1}^{n} w_{j}=1$, which is different from that in Model 1, that is, $\sum_{j=1}^{n} w_{j}^{2}=1$.

Solving Model 2 by LINGO or MATLAB software package, we can obtain the optimal weights of criteria as $w=\left(w_{1}, w_{2}, \cdots, w_{m}\right)^{T}$. 


\section{A q-ROF-GLDS method for MCDM problems}

As discussed in the Introduction, the original GLDS method (Wu \& Liao, 2019) has some limitations. Firstly, in the original GLDS method, the overall lost dominance score only retains the largest value but ignores other values. This fits the MCDM problems in which DMs are risk-averse, but fails to deal with the case that DMs are risk-preferred. Subsequently, the original GLDS method (Wu \& Liao, 2019) can only be applied to address the MCDM problems with probability linguistic term information but cannot deal with q-ROF information. In this section, the GLDS method is investigated in the context of q-ROFSs based on the defined dominance flow, order score and aggregation function. The improved q-ROF GLDS method includes three parts: calculating the dominance flows of alternatives, determining the order scores of alternatives, and the final aggregation.

\subsection{Calculating the dominance flows of alternatives}

For two alternatives $A_{i}$ and $A_{v}(v \neq i ; i, v=1,2, \cdots, m)$, the dominance flow of the former over the later under criterion $c_{j}$ can be defined as

$$
D F_{j}\left(A_{i}, A_{v}\right)=\left\{\begin{array}{cc}
s\left(A_{i j}\right)-s\left(A_{v j}\right), & \text { if } s\left(A_{i j}\right) \geq s\left(A_{v j}\right) \\
0 \quad & \text { if } s\left(A_{i j}\right)<s\left(A_{v j}\right)
\end{array}, \text { for } j=1,2, \ldots, n,\right.
$$

where $s\left(A_{i j}\right)$ and $s\left(A_{v j}\right)$ are derived by Eq. (3), representing the score values of the evaluations $\left(\alpha_{i j}^{C N}, \beta_{i j}^{C N}\right)$ and $\left(\alpha_{v j}^{C N}, \beta_{v j}^{C N}\right)$, respectively.

As we know, the evaluation standards regarding the performances of alternatives may be different under different criteria. Thus, it would be inappropriate to integrate the dominance flows of alternatives directly. In this sense, all the obtained dominance flows need to be normalized. In the following, both the linear normalization and vector normalization methods are respectively used to derive the normalized dominance flows of alternatives. By vector normalization, we have

$$
D F_{j}^{N}\left(A_{i}, A_{v}\right)=D F_{j}\left(A_{i}, A_{v}\right) / \sqrt{\sum_{i=1}^{m} \sum_{v=1}^{m}\left(D F_{j}\left(A_{i}, A_{v}\right)\right)^{2}} .
$$

After normalization, for criterion $c_{j}$, the gained dominance score of alternative $A_{i}$ to alternative $A_{v}$ can be defined by

$$
\operatorname{GDS}_{j}\left(A_{i}, A_{v}\right)=\sum_{v=1}^{m} D F_{j}^{N}\left(A_{i}, A_{v}\right) .
$$

Taking into account the weights of criteria, the comprehensive gained dominance score of alternative $A_{i}$ can be determined as

$$
\operatorname{CGDS}\left(A_{i}\right)=\sum_{j=1}^{n} w_{j} \cdot G D S_{j}\left(A_{i}, A_{v}\right) \text {. }
$$

In the prospect theory, Kahneman and Tversky (2013) considered that DMs have different attitudes on gains and losses under distinct scenarios. Kahneman and Tversky (2013) also deemed that the majority of DMs are risk-averse for gains but risk-preferred for losses. In this 
sense, DMs with different risk attitudes would have completely different ways to handle the lost dominance flows of alternatives. Therefore, different from the original gained dominance score function, we shall discuss the lost dominance scores of alternatives from two aspects, i.e., risk-averse and risk-referred.

If a DM is risk-averse, then, for criterion $c_{j}$, the lost dominance score of $A_{i}$ to $A_{v}$ can be defined as

$$
\operatorname{LDS}_{j}^{1}\left(A_{v}, A_{i}\right)=\max _{v}\left\{D F_{j}^{N}\left(A_{v}, A_{i}\right)\right\} .
$$

If a DM is are risk-referred, then, for criterion $c_{j}$, the lost dominance score of $A_{i}$ to $A_{v}$ can be determined as

$$
\operatorname{LDS}_{j}^{2}\left(A_{v}, A_{i}\right)=\sum_{v=1}^{m} D F_{j}^{N}\left(A_{v}, A_{i}\right) .
$$

The comprehensive lost dominance score of $A_{i}$ is defined as

$$
\operatorname{CLDS}\left(A_{i}\right)=\sum_{v=1}^{m} w_{j} \cdot \operatorname{LDS}_{j}^{1}\left(A_{v}, A_{i}\right) \text { or } \sum_{v=1}^{m} w_{j} \cdot \operatorname{LDS}_{j}^{2}\left(A_{v}, A_{i}\right) \text {. }
$$

where $\operatorname{LDS}_{j}\left(A_{v}, A_{i}\right)$ can be derived from Eqs (30-1) or (30-2), depending on the types of DMs.

Besides, we can derivate the ascending order $R_{i}^{1}$ and descending order $R_{i}^{2}$ of alternative $A_{i}$ according to $\operatorname{CGDS}\left(A_{i}\right)$ and $\operatorname{CLDS}\left(A_{i}\right)$, respectively.

\subsection{Determining the order scores of alternatives}

This part investigates the order scores of alternatives. Assume that $\eta_{i v}^{j}$ equals to one if alternative $A_{i}$ is superior to $A_{v}(i \neq v, v=1,2, \cdots, m)$ under criterion $c_{j}$; otherwise, $g \eta_{i v}^{j}$ equals to zero. In this sense, from the aspect of gains, we define the order score of $A_{i}$ to $A_{v}$ as

$$
g \eta_{i v}^{j}=\left\{\begin{array}{l}
1, \text { if } s\left(A_{i j}\right) \geq s\left(A_{v j}\right) \\
0, \text { if } s\left(A_{i j}\right)<s\left(A_{v j}\right)
\end{array},\right.
$$

where $s\left(A_{i j}\right)$ and $s\left(A_{v j}\right)$ are calculated by Eq. (3), denoting the score values of $\left(\alpha_{i j}, \beta_{i j}\right)$ and $\left(\alpha_{v j}, \beta_{v j}\right)$, respectively.

For all criteria $c_{j}(j=1,2, \ldots, n)$, we obtain the order score of alternative $A_{i}$ to all the other alternatives as

$$
g \eta_{i}=\sum_{j=1}^{n} \sum_{v \neq i, v=1}^{m} g \eta_{i v}^{j} .
$$

From the aspect of losses, we obtain the order score of $A_{i}$ to $A_{v}$ as

$$
\operatorname{l\eta }_{i v}^{j}=\left\{\begin{array}{ll}
0, & \text { if } s\left(A_{i j}\right) \geq s\left(A_{v j}\right) \\
1, & \text { if } s\left(A_{i j}\right)<s\left(A_{v j}\right)
\end{array} .\right.
$$

For all criteria $c_{j}(j=1,2, \ldots, n)$, we obtain the order score of alternative $A_{i}$ to all the other alternatives as

$$
\operatorname{l\eta } \eta_{i}=\sum_{j=1}^{n} \sum_{v \neq i, v=1}^{m} \operatorname{l\eta }_{i v}^{j}
$$




\subsection{The final aggregation}

At the final stage, we shall apply the aggregation function shown as Eq. (36) to integrate the results obtained in both Sections 4.1 and 4.2 to derive the final ranking of alternatives:

$$
C S_{i}=\operatorname{CGDS}\left(A_{i}\right) \cdot R_{i}^{1} \cdot\left(g \eta_{i} / \sum_{i=1}^{m} g \eta_{i}\right)-\operatorname{CLDS}\left(A_{i}\right) \cdot\left(m-R_{i}^{2}+1\right) \cdot\left(l \eta_{i} / \sum_{i=1}^{m} \eta_{i}\right),
$$

where $g \eta_{i}$ and $l \eta_{i}$ represent the order scores of alternative $A_{i}$ from the aspects of gains and losses, respectively. $C S_{i}$ means the comprehensive score of alternative $A_{i}$.

The final ranking of alternatives is obtained in descending orders of $C S_{i}(i=1,2, \ldots, m)$. The lager the value of $C S_{i}$ is, the better the alternative $A_{i}$ should be.

\subsection{Procedure of the q-ROF-GLDS method for multiple experts MCDM problems}

In this subsection, a new q-ROF MCDM method is proposed, in which both the weights of DMs and criteria are considered simultaneously. The procedure of the proposed method is given below step by step and lists in Algorithm 1:

Step 1. Construct an MCDM problem with q-ROF information, which contains a set of alternatives $A_{i}(i=1,2, \ldots, m)$ and a collective of criteria $c_{j}(j=1,2, \ldots, n)$. There are $t \mathrm{DMs}$ $e_{k}(k=1,2, \cdots, t)$ who are invited to evaluate the alternatives over the criteria and then give their opinions in q-ROFNs, i.e., $\left(d_{i j}^{(k)}\right)_{m \times n}=\left(\alpha_{i j}^{(k)}, \beta_{i j}^{(k)}\right)_{m \times n}$.

Step 2. Normalize all the opinions provided by the DMs by Eq. (7).

Step 3. Calculate the weight vector of DMs by Eq. (21).

Step 4. Calculate the weight vector of the criteria by Eq. (25) or Model 2.

Step 5. Determine the comprehensive gained and lost dominance flow scores $\operatorname{CGDS}\left(A_{i}\right)$ and $\operatorname{CLDS}\left(A_{i}\right)$ of the alternatives by Eqs (29) and (31), respectively.

Step 6. Derive the order scores, $R_{i}^{1}$ and $R_{i}^{2}$, of alternatives from the aspects of gains and losses by Eqs (32)-(35).

Step 7. Integrate the comprehensive dominance flow scores and the order scores of each alternative by Eq. (36), and obtain the comprehensive scores of alternatives.

Step 8. Rank the alternatives according to the descending orders of $C S_{i}$.

\section{Algorithm 1 (The Q-ROF-GLDS method)}

Input: DMs' evaluation values with q-ROFNs.

Output: The ranking of alternatives.

1. Construct $\left(d_{i j}^{(k)}\right)_{m \times n}$ according to DMs' opinions.

2. Normalize all the opinions using Eq. (7).

3. Derive the weights of DMs by Eq. (21).

4. Derive the weights of criteria through Eq. (25) or Model 2.

5. Determine $\operatorname{CGDS}\left(A_{i}\right)$ and $\operatorname{CLDS}\left(A_{i}\right)$ by Eqs (29) and (31), respectively. 


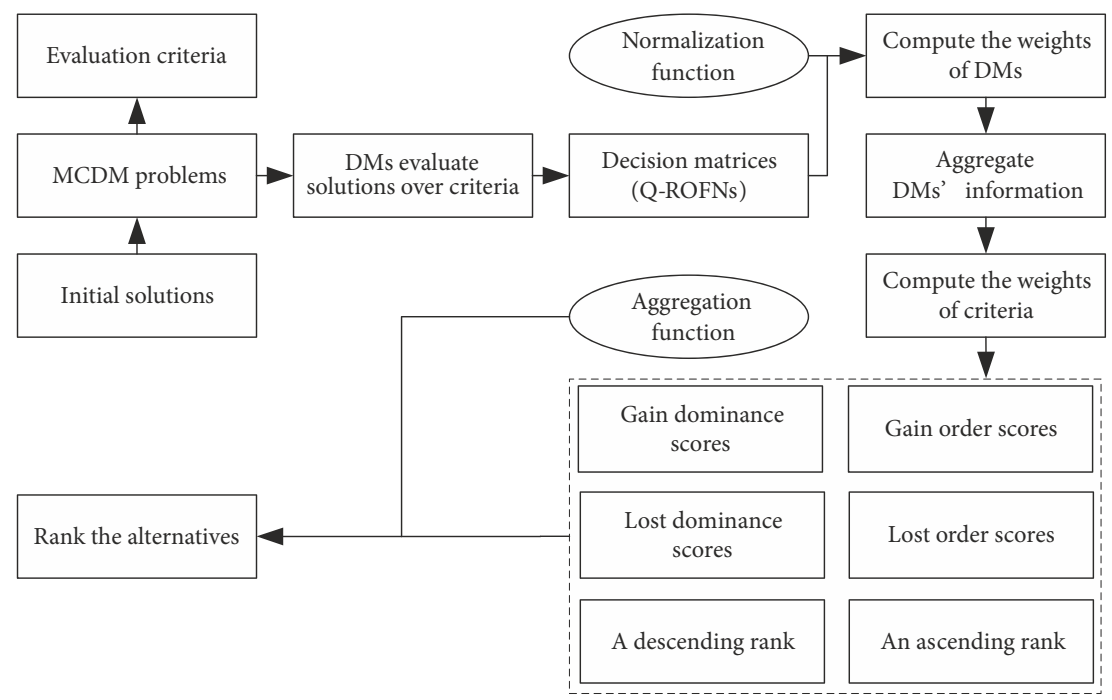

Figure 1. The flowchart of the q-R-GLDS method for MCDM problems

6. Calculate the values of $g \eta_{i}, l \eta_{i}, R_{i}^{1}$ and $R_{i}^{2}$ by Eqs (32)-(35), respectively.

7. Calculate the value of $C S_{i}$ for each alternative based on Eq. (36).

8. Rank the alternatives in descending order of $C S_{i}$.

Compared with the original GLDS method (Wu \& Liao, 2019), the improved q-ROF GLDS method involves some novelties, including new methods to derive the weights of DMs and criteria, new function of the order scores of alternatives and new aggregation function shown as Eq. (45). In particular, for the order scores of alternatives, we discuss the lost dominance scores from two aspects, i.e., the DMs are risk-averse or risk-preference. In this way, the DMs would be free to choose an appropriate one for MCDM problems.

To clarify the improved q-ROF GLDS method, we further illustrate it by a flowchart shown as Figure 1.

\section{Case study: Investment evaluation of BE angle capital in China}

In this section, a case study regarding investment evaluation of BE angle capital is presented to demonstrate the applicability of the proposed q-ROF GLDS method. After that, detailed comparisons with existing methods are given to verify the validity of the proposed method.

\subsection{Case description}

In recent years, the Angel investment, Internet Finance, and other investment/financial services have developed rapidly, which provides a strong capital thrust for both innovation and entrepreneurship. Meanwhile, the main body of entrepreneurship has also been translated from "small group" to "public", leading to more and more groups devoting themselves to entrepreneurship. For this reason, the innovation and entrepreneurship have become a value orientation, lifestyle and atmosphere. From Figure 2, we can see that the scale of venture 
capital in China is gradually decreasing, mainly due to the slowdown of China's economic growth. Most Chinese venture capital institutes are cautious because of the uncertain economic outlook, the slowdown of China's economy and the expectation of interest rate hikes ${ }^{1}$. In addition, the investment amount has a decreasing trend compared with the same quarter. The total amount of early investment cases also decreases from 680 in Q2'16 to 528 in Q2'18, resulting in a significant decline. How to select high-quality angel-round investment projects has become a difficult decision-making problem.

The BE company is an innovative private equity parent fund and managed by the world's top fund management team. It is praised by the world because it often tracks or follows up outstanding projects. The BE company mainly concentrates on the seed or angel investment, especially focusing on industrial internet, Internet finance, artificial intelligence, big data healthcare, intelligent hardware, and block chains. The investment team is composed of well-known venture capitalists from various fields, such as Harvard University postdoctoral students, president of Beijing University Institute of Industrial Technology and Minister of Science and Technology Development.

Recently, the BE company has a fund ready to put into Angel Round project through the company's preliminary screening from 304 projects. For the five preliminary screening projects, it still needs to further screen out the optimal one for investment. A brief description of these five projects is given in Table 4 .

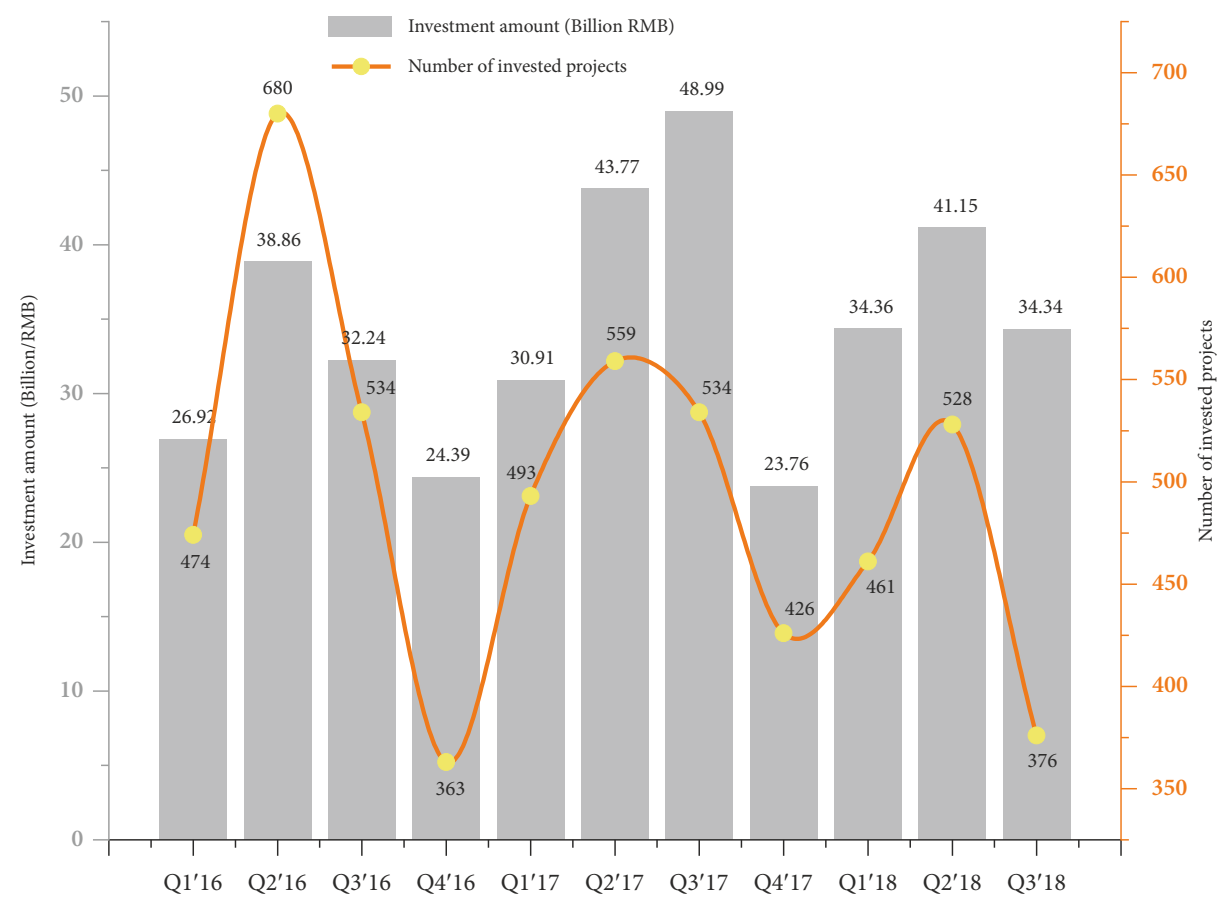

Figure 2. Changes in China's early investment in total from the first quarter of 2016 to the third quarter of 2018

\footnotetext{
${ }^{1}$ https://www.pedate.com
} 
Table 4. Brief descriptions of the five investment projects

\begin{tabular}{|l|l|}
\hline$A_{1}$ & $\begin{array}{l}\text { The aim of this project is to develop a new rabies vaccine for veterinary use. The vaccine uses the } \\
\text { world's leading chimeric antigen vaccine technology, i.e., the food-grade engineering bacteria to } \\
\text { express viral characteristic proteins }\end{array}$ \\
\hline$A_{2}$ & $\begin{array}{l}\text { The company was established in } 2017 \text { with } 5 \text { million RMB registered capital. It is committed } \\
\text { to the research and development, production and sales of temperature-sensitive intelligent cell } \\
\text { petri dishes }\end{array}$ \\
\hline$A_{3}$ & $\begin{array}{l}\text { It is a public welfare organization focusing on helping college students especially the } \\
\text { disadvantaged groups. Based on the dual-track operation of campus associations and public } \\
\text { welfare organizations, a closed-loop ecological circle of mentors and trainees is built on the } \\
\text { platform of Public Number }\end{array}$ \\
\hline$A_{4}$ & $\begin{array}{l}\text { It is an intelligent toothbrush that integrates visual brushing experience, timely oral examination, } \\
\text { personalized customized guidance. The project has been supported by the State Key Laboratory } \\
\text { of Oral Diseases and the Institute of Computing, Chinese Academy of Sciences }\end{array}$ \\
\hline$A_{5}$ & $\begin{array}{l}\text { The company uses the world's first isolation dual network structure technology to produce high- } \\
\text { performance polymer thermal conductive materials, to solve the worldwide technical problems } \\
\text { of thermal conductivity }\end{array}$ \\
\hline
\end{tabular}

To select the invested projects accurately, four professional investors $E^{k}(k=1,2,3,4)$ of the BE Company score those five projects strictly by presentation. Because the information is not comprehensive, investors cannot give precise values. To express the investors' opinions as accurately as possible, their evaluations were made by two variables: membership degrees and non-membership degrees of q-ROFSs. All the investors $E^{k}(k=1,2,3,4)$ evaluated the five alternatives in terms of six criteria in Table 5 and then gave their decision matrices as $D^{(k)}(k=1,2,3,4)$.

Table 5. Criteria for investment projects evaluation

\begin{tabular}{|l|l|}
\hline$c_{1}$ (Market pain point) & $\begin{array}{l}\text { It mainly describes the extent to which the problem solved by the project } \\
\text { affects the market }\end{array}$ \\
\hline$c_{2}$ (Market capacity) & $\begin{array}{l}\text { It is an evaluation of the future development potential of entrepreneurship } \\
\text { projects }\end{array}$ \\
\hline $\begin{array}{c}c_{3} \text { (Product and } \\
\text { service innovation) }\end{array}$ & $\begin{array}{l}\text { This index mainly describes the level of innovation compared with similar } \\
\text { previous products and services }\end{array}$ \\
\hline$c_{4}$ (Business model) & $\begin{array}{l}\text { It mainly describes whether the business logic of entrepreneurship project } \\
\text { conforms to the market law or not }\end{array}$ \\
\hline$c_{5}$ (Project team) & $\begin{array}{l}\text { It indicates the team literacy, such as complementarity of entrepreneurial } \\
\text { team competence, and tacit understanding of cooperation }\end{array}$ \\
\hline $\begin{array}{c}c_{6} \text { (Performance of } \\
\text { financing plan) }\end{array}$ & It evaluates the rationality and reliability of future financial forecasting \\
\hline
\end{tabular}

$$
D^{(1)}=\left(\begin{array}{lllllll}
(0.682,0.213) & (0.384,0.625) & (0.721,0.236) & (0.423,0.488) & (0.689,0.231) & (0.723,0.281) \\
(0.732,0.189) & (0.643,0.325) & (0.431,0.582) & (0.631,0.331) & (0.652,0.209) & (0.538,0.232) \\
(0.483,0.211) & (0.589,0.108) & 0.397,0.281) & (0.723,0.226) & (0.693,0.233) & (0.529,0.237) \\
(0.543,0.188) & (0.573,0.109) & (0.430,0.215) & (0.531,0.119) & (0.558,0.221) & (0.543,0.209) \\
(0.521,0.187) & (0.733,0.412) & (0.513,0.407) & (0.438,0.109) & (0.670,0.432) & (0.597,0.202)
\end{array}\right) ;
$$




$$
\begin{aligned}
& D^{(2)}=\left(\begin{array}{ccccccc}
(0.667,0.199) & (0.364,0.695) & (0.761,0.284) & (0.469,0.397) & (0.642,0.233) & (0.711,0.221) \\
(0.752,0.149) & (0.593,0.312) & (0.531,0.592) & (0.611,0.351) & (0.612,0.219) & (0.539,0.230) \\
(0.513,0.231) & (0.599,0.118) & (0.357,0.261) & (0.733,0.220) & (0.698,0.231) & (0.539,0.233) \\
(0.547,0.186) & 0.583,0.119) & (0.480,0.205) & (0.532,0.129) & (0.598,0.203) & (0.573,0.219) \\
(0.531,0.197) & (0.753,0.422) & (0.533,0.417) & (0.448,0.113) & (0.681,0.437) & (0.586,0.214)
\end{array}\right) ; \\
& D^{(3)}=\left(\begin{array}{lllllll}
(0.691,0.313) & (0.484,0.524) & (0.756,0.486) & (0.623,0.312) & (0.678,0.442) & (0.621,0.412) \\
(0.812,0.199) & (0.523,0.425) & (0.531,0.562) & (0.731,0.431) & (0.752,0.312) & (0.638,0.242) \\
(0.453,0.210) & (0.689,0.328) & (0.497,0.221) & (0.721,0.220) & (0.652,0.802) & (0.629,0.287) \\
(0.596,0.187) & 0.566,0.139) & (0.530,0.205) & (0.530,0.113) & (0.548,0.213) & (0.572,0.309) \\
(0.571,0.183) & (0.743,0.402) & (0.514,0.457) & (0.448,0.179) & (0.680,0.431) & (0.523,0.301)
\end{array}\right) ; \\
& D^{(4)}=\left(\begin{array}{lllllll}
(0.651,0.613) & (0.489,0.724) & (0.656,0.536) & (0.626,0.510) & (0.698,0.402) & (0.691,0.372) \\
(0.704,0.229) & (0.543,0.468) & (0.531,0.662) & (0.702,0.531) & (0.682,0.372) & (0.608,0.222) \\
(0.457,0.210) & (0.659,0.308) & (0.501,0.221) & (0.691,0.320) & (0.652,0.193) & (0.649,0.286) \\
(0.599,0.180) & (0.587,0.349) & (0.538,0.405) & (0.549,0.103) & 0.524,0.303) & (0.502,0.209) \\
(0.581,0.180) & (0.793,0.502) & (0.524,0.497) & (0.459,0.169) & (0.700,0.562) & (0.528,0.321)
\end{array}\right) .
\end{aligned}
$$

\subsection{Solving the case using the improved q-ROF GLDS method}

In what follows, we use the q-ROF GLDS method to solve the case.

Step 1. Related information is given in Section 5.1.

Step 2. Note that all the criteria in this MCDM problem are benefit. So the normalization process is omitted.

Step 3. Using Eqs (8)-(13), the positive ideal solution PIS, left negative ideal solution NIS and right negative ideal solution NIS ${ }^{r}$ can be determined as:

$$
\begin{aligned}
& P I S=\left(\begin{array}{lllllll}
(0.673,0.335) & (0.430,0.642) & (0.724,0.386) & (0.535,0.427) & (0.677,0.327) & (0.687,0.322) \\
(0.750,0.192) & (0.576,0.383) & (0.506,0.560) & (0.669,0.411) & (0.675,0.278) & (0.581,0.232) \\
(0.477,0.216) & (0.634,0.216) & 0.438,0.246) & (0.717,0.247) & (0.674,0.365) & (0.586,0.261) \\
(0.571,0.185) & 0.577,0.179) & 0.495,0.258) & 0.536,0.116) & (0.557,0.235) & (0.548,0.237) \\
(0.551,0.187) & (0.756,0.435) & (0.521,0.445) & (0.448,0.143) & (0.683,0.466) & (0.559,0.260)
\end{array}\right) ; \\
& N I S^{l}=\left(\begin{array}{lllllll}
(0.651,0.613) & (0.364,0.695) & (0.656,0.539) & (0.423,0.488) & (0.678,0.442) & (0.621,0.412) \\
(0.704,0.229) & 0.543,0.468) & (0.531,0.662) & 0.702,0.531) & (0.682,0.372) & (0.538,0.232) \\
(0.453,0.210) & 0.689,0.328) & 0.357,0.261) & 0.691,0.320) & (0.652,0.802) & (0.573,0.219) \\
(0.543,0.188) & (0.587,0.349) & (0.538,0.405) & (0.532,0.129) & (0.548,0.213) & (0.572,0.309) \\
(0.521,0.187) & (0.733,0.412) & (0.524,0.497) & (0.459,0.169) & (0.700,0.562) & (0.523,0.301)
\end{array}\right) ; \\
& N I S^{r}=\left(\begin{array}{lllllll}
(0.682,0.213) & (0.484,0.524) & (0.761,0.284) & (0.623,0.312) & (0.689,0.231) & (0.711,0.221) \\
(0.812,0.199) & (0.643,0.325) & (0.531,0.562) & (0.731,0.431) & (0.752,0.312) & (0.638,0.242) \\
(0.513,0.231) & (0.599,0.118) & (0.501,0.221) & (0.733,0.220) & (0.698,0.231) & (0.629,0.287) \\
(0.596,0.187) & (0.583,0.119) & (0.530,0.205) & (0.549,0.103) & (0.598,0.203) & (0.573,0.219) \\
(0.581,0.180) & (0.743,0.402) & (0.533,0.417) & (0.448,0.113) & (0.680,0.431) & (0.597,0.202)
\end{array}\right) .
\end{aligned}
$$

Calculate the distances from PIS, NIS $S^{l}$ NIS $S^{r}$ to $D^{N(k)}$ through Eqs. (14)-(16), respectively. The calculation results are given in Table 6. 
Table 6. Distances between PIS / NIS $/ N I S^{r}$ and $D^{N(k)}$

\begin{tabular}{|c|c|c|c|}
\hline & $d\left(\alpha_{i j}^{*}, \alpha_{i j}^{N(k)}\right)$ & $d\left(\alpha_{i j}^{l-}, \alpha_{i j}^{N(k)}\right)$ & $d\left(\alpha_{i j}^{l+}, \alpha_{i j}^{N(k)}\right)$ \\
\hline$D^{(1)}$ & 0.0706 & 0.0993 & 0.0538 \\
\hline$D^{(2)}$ & 0.0662 & 0.0981 & 0.0374 \\
\hline$D^{(3)}$ & 0.0537 & 0.0745 & 0.0467 \\
\hline$D^{(4)}$ & 0.0967 & 0.0480 & 0.1117 \\
\hline
\end{tabular}

Next, the relative closeness of each DM can be calculate by Eq. (20), which are $R C^{(1)}=-0.6092, R C^{(2)}=-0.1578, R C^{(3)}=-0.3909$ and $R C^{(4)}=-0.9104$. We obtain the weight vector of the DMs as $\lambda=(0.2589,0.2153,0.2378,0.2880)^{T}$. Correspondingly, through Eq. (22), the comprehensive decision matrix $D^{C N}$ is derived as:

$D^{C N}=\left(\begin{array}{lllllll}(0.628,0.312) & (0.439,0.640) & (0.685,0.369) & (0.522,0.425) & (0.637,0.317) & (0.651,0.317) \\ (0.741,0.192) & (0.544,0.381) & (0.508,0.601) & 0.639,0.409) & (0.643,0.274) & (0.584,0.231) \\ (0.475,0.215) & (0.630,0.194) & (0.445,0.244) & 0.686,0.247) & (0.574,0.296) & (0.593,0.261) \\ (0.574,0.185) & (0.578,0.165) & 0.498,0.253) & 0.536,0.115) & (0.555,0.236) & (0.545,0.232) \\ (0.553,0.186) & (0.758,0.434) & (0.489,0.445) & (0.449,0.140) & (0.684,0.467) & (0.558,0.257)\end{array}\right)$.

Step 4. We can obtain the distance between $A_{i}$ and $A_{v}(i, j=1,2, \cdots, 5 ; i \neq v)$ by Eq. (5) and the results are given in Table 7 . Then the weight vector of the criteria can be determined as $w=(0.1425,0.3050,0.1823,0.3179,0.0949,0.0427)^{T}$ by solving Model 2.

Table 7. Distances between $A_{i}$ and $A_{v}$

\begin{tabular}{|c|c|c|c|c|c|c|}
\hline & $c_{1}$ & $c_{2}$ & $c_{3}$ & $c_{4}$ & $c_{5}$ & $c_{6}$ \\
\hline$d\left(A_{1}, A_{2}\right)$ & 0.000738334 & 0.114482567 & 0.047577225 & 0.108655966 & 0.001588504 & 0.017498700 \\
\hline$d\left(A_{1}, A_{3}\right)$ & 0.029994658 & 0.143397068 & -0.00195316 & 0.029515603 & 0.005730273 & 0.009710084 \\
\hline$d\left(A_{1}, A_{4}\right)$ & 0.055717892 & 0.113831615 & 0.054814094 & 0.091962687 & 0.019909988 & 0.027317554 \\
\hline$d\left(A_{1}, A_{5}\right)$ & 0.047405853 & 0.110511767 & 0.012565259 & 0.107207380 & 0.055263030 & 0.017654395 \\
\hline$d\left(A_{2}, A_{3}\right)$ & 0.064982305 & 0.026438704 & 0.026883749 & 0.105790937 & 0.003747790 & 0.001228100 \\
\hline$d\left(A_{2}, A_{4}\right)$ & 0.029253874 & 0.040886098 & 0.043081391 & 0.012478694 & 0.012618900 & 0.001484741 \\
\hline$d\left(A_{2}, A_{5}\right)$ & 0.036401625 & 0.031671739 & 0.079649299 & 0.001286251 & 0.043933305 & 0.000675091 \\
\hline$d\left(A_{3}, A_{4}\right)$ & 0.007587528 & 0.005136365 & 0.003243576 & 0.059672057 & 0.005089975 & 0.004497936 \\
\hline$d\left(A_{3}, A_{5}\right)$ & 0.004636554 & 0.003228254 & 0.051321343 & 0.093020397 & 0.025690926 & 0.001346606 \\
\hline$d\left(A_{4}, A_{5}\right)$ & 0.000392686 & 0.000589744 & 0.035632533 & 0.006089969 & 0.009569901 & 0.001133685 \\
\hline
\end{tabular}

Step 5. Both the gained dominance scores and order scores of alternatives can be obtained through Eqs (28)-(31). The calculation results are shown in Table 8. 
Table 8. The overall gained dominance scores of the alternatives

\begin{tabular}{|c|c|c|c|c|c|c|c|}
\hline & $c_{1}$ & $c_{2}$ & $c_{3}$ & $c_{4}$ & $c_{5}$ & $c_{6}$ & $g \eta_{i}$ \\
\hline$A_{1}$ & 0.113258321 & 0.000000000 & 1.215184183 & 0.000000000 & 0.554407835 & 0.608916305 & 11 \\
\hline$A_{2}$ & 1.780408407 & 0.307716276 & 0.000000000 & 0.229180789 & 1.512316606 & 1.480049032 & 14 \\
\hline$A_{3}$ & 0.000000000 & 0.811232151 & 0.597524551 & 1.096866379 & 0.143240745 & 0.547998469 & 13 \\
\hline$A_{4}$ & 0.457813619 & 0.736450439 & 0.765097154 & 0.983839895 & 0.546472129 & 0.138015221 & 15 \\
\hline$A_{5}$ & 0.325214966 & 0.668822230 & 0.189099448 & 0.444435904 & 0.000000000 & 0.000000000 & 7 \\
\hline
\end{tabular}

Step 6. Based on Eqs (32)-(35), the lost dominance scores and order scores of alternatives $A_{i}(i=1,2, \cdots, 5)$ can be determined. The calculation results are presented in Table 9.

Table 9. The overall lost dominance scores of the alternatives

\begin{tabular}{|c|c|c|c|c|c|c|c|}
\hline & $c_{1}$ & $c_{2}$ & $c_{3}$ & $c_{4}$ & $c_{5}$ & $c_{6}$ & $l \eta_{i}$ \\
\hline$A_{1}$ & 0.736982767 & 1.836304935 & 0.000000000 & 1.627465109 & 0.239477193 & 0.217783182 & 13 \\
\hline$A_{2}$ & 0.000000000 & 0.605439832 & 1.593272272 & 0.710741955 & 0.000000000 & 0.000000000 & 10 \\
\hline$A_{3}$ & 1.190016050 & 0.000000000 & 0.224236826 & 0.000000000 & 0.849614739 & 0.258395073 & 11 \\
\hline$A_{4}$ & 0.330648697 & 0.018695428 & 0.112521757 & 0.028256621 & 0.244767664 & 0.873369945 & 9 \\
\hline$A_{5}$ & 0.419047799 & 0.063780901 & 0.836874481 & 0.387859282 & 1.422577720 & 1.425430828 & 17 \\
\hline
\end{tabular}

Step 7. Calculate the comprehensive score of each alternative by Eq. (36). Then, we have $C S_{i}=(-0.7626,0.2053,0.2662,0.1357,-0.1133)^{T}$.

Step 8. We rank the alternatives in descending orders of $C S_{i}(i=1,2, \ldots, 5)$, and obtain the ranking of the alternatives as $A_{3} \succ A_{2} \succ A_{4} \succ A_{1} \succ A_{5}$. Thus, $A_{3}$ is the optimal investment project.

\subsection{Comparative and sensitive analyses}

In this subsection, detailed comparisons with existing methods are given to illustrate the validity and superiority of the q-ROF GLDS method.

\subsubsection{Comparative analyses with other methods}

(1) Solving the case by the q-ROF TOPSIS method

We address the case in Section 5.1 by the q-ROF TOPSIS method (Liu \& Wang, 2018) and all the calculation procedures are presented step by step below.

Step 1. From Section 5.2, we know the normalized comprehensive decision matrix as $D^{C N}$. Next, both the positive ideal solution pis and the negative ideal solution nis can be determined as:

pis $=((0.7408,0.1921),(0.6300,0.1939),(0.6846,0.3693),(0.6861,0.2468),(0.6432,0.2742),(0.5844,0.2310))$;

nis $=((0.4754,0.2146),(0.4389,0.6397),(0.5081,0.6012),(0.5216,0.4251),(0.5741,0.2956),(0.5584,0.2570))$. 
Step 2. By Eqs (37) and (38), we calculate the distance from the evaluation values of each alternative $A_{i}(i=1,2, \ldots, 5)$ to $p i s$ and nis, respectively. All the calculation results are given in Table 10.

$d\left(p i s, A_{i}\right)=$
$\sum_{j=1}^{n} w_{j}\left\{\begin{array}{l}\frac{\left|q_{2}-q_{1}\right|+1}{q_{*}} \cdot \sqrt{\left(\left(\alpha_{i j}^{C N}\right)^{q_{1}}-\left(\alpha_{j}^{p i s}\right)^{q_{2}}\right)^{2}+\left(\left(\beta_{i j}^{C N}\right)^{q_{1}}-\left(\beta_{j}^{p i s}\right)^{q_{2}}\right)^{2}+\left(\left(\alpha_{i j}^{C N}\right)^{q_{1}}-\left(\alpha_{j}^{p_{i}}\right)^{q_{2}}\right)\left(\left(\beta_{i j}^{C N}\right)^{q_{1}}-\left(\beta_{j}^{p i s}\right)^{q_{2}}\right)}, \text { otherwise } \\ \frac{1}{q_{*}} \cdot \sqrt{\left(\left(\alpha_{i j}^{C N}\right)^{q_{1}}-\left(\alpha_{j}^{p i s}\right)^{q_{2}}\right)^{2}+\left(\left(\beta_{i j}^{C N}\right)^{q_{1}}-\left(\beta_{j}^{p i s}\right)^{q_{2}}\right)^{2}+\left(\left(\alpha_{i j}^{C N}\right)^{q_{1}}-\left(\alpha_{j}^{p i s}\right)^{q_{2}}\right)\left(\left(\beta_{i j}^{C N}\right)^{q_{1}}-\left(\beta_{j}^{p i s}\right)^{q_{2}}\right)}, \text { if }\left(\alpha_{i j}\right)^{q_{1}}=\left(\alpha_{j}^{p i s}\right)^{q_{2}},\left(\beta_{i j}\right)^{q_{1}}=\left(\beta_{j}^{p i s}\right)^{q_{2}}, q_{1} \neq q_{2}\end{array}\right.$

and

$d\left(n i s, A_{i}\right)=$

$\sum_{j=1}^{n} w_{j}\left\{\begin{array}{l}\frac{\left|q_{2}-q_{1}\right|+1}{q_{*}} \cdot \sqrt{\left(\left(\alpha_{i j}^{C N}\right)^{q_{1}}-\left(\alpha_{j}^{n i s}\right)^{q_{2}}\right)^{2}+\left(\left(\beta_{i j}^{C N}\right)^{q_{1}}-\left(\beta_{j}^{n i s}\right)^{q_{2}}\right)^{2}+\left(\left(\alpha_{i j}^{C N}\right)^{q_{1}}-\left(\alpha_{j}^{n i s}\right)^{q_{2}}\right)\left(\left(\beta_{i j}^{C N}\right)^{q_{1}}-\left(\beta_{j}^{n i s}\right)^{q_{2}}\right)}, \text { otherwise } \\ \frac{1}{q_{*}} \cdot \sqrt{\left(\left(\alpha_{i j}^{C N}\right)^{q_{1}}-\left(\alpha_{j}^{n i s}\right)^{q_{2}}\right)^{2}+\left(\left(\beta_{i j}^{C N}\right)^{q_{1}}-\left(\beta_{j}^{n i s}\right)^{q_{2}}\right)^{2}+\left(\left(\alpha_{i j}^{C N}\right)^{q_{1}}-\left(\alpha_{j}^{n i s}\right)^{q_{2}}\right)\left(\left(\beta_{i j}^{C N}\right)^{q_{1}}-\left(\beta_{j}^{n i s}\right)^{q_{2}}\right)}, \text { if }\left(\alpha_{i j}\right)^{q_{1}}=\left(\alpha_{j}^{n i s}\right)^{q_{2}},\left(\beta_{i j}\right)^{q_{1}}=\left(\beta_{j}^{n i s}\right)^{q_{2}} \text {, and } q_{1} \neq q_{2}\end{array}\right.$.

Table 10. Distances between pis / nis and $A_{i}$

\begin{tabular}{|c|c|c|c|c|c|}
\hline Distance & $A_{1}$ & $A_{2}$ & $A_{3}$ & $A_{4}$ & $A_{5}$ \\
\hline$d\left(p i s, A_{i}\right)$ & 0.1677 & 0.1363 & 0.0435 & 0.1135 & 0.1541 \\
\hline$d\left(\right.$ nis, $\left.A_{i}\right)$ & 0.0547 & 0.1777 & 0.1426 & 0.1824 & 0.2051 \\
\hline
\end{tabular}

Step 3. Determine the relative coefficient value of each alternative by Eq. (39):

$$
R C_{i}=d\left(n i s, A_{i}\right) /\left(d\left(\text { pis, } A_{i}\right)+d\left(n i s, A_{i}\right)\right) .
$$

Then, we have $R C_{1}=0.2461, R C_{2}=0.5660, R C_{3}=0.7662, R C_{4}=0.6164$ and $R C_{5}=0.5710$.

Step 4. Rank the alternatives in descending orders of $R C_{i}$. The ranking of the alternatives is $A_{3} \succ A_{4} \succ A_{5} \succ A_{2} \succ A_{1}$. Thus, the optimal investment project is $A_{3}$.

(2) Solving the case by the q-ROF VIKOR method

Below we shall tackle this case by the q-ROF VIKOR method and related procedures are shown in detail below.

Step 1. Same as above.

Step 2. Calculate the values of group utility measure $G U_{i}$ and individual regret measure $I R_{i}$ by Eq. (40). The results are shown in Table 11.

$$
G U_{i}=\sum_{j=1}^{n} w_{j} \frac{d\left(c_{j}^{+}, d_{i j}^{c n}\right)}{d\left(c_{j}^{+}, c_{j}^{-}\right)}, I R_{i}=\max _{j}\left\{w_{j} \frac{d\left(c_{j}^{+}, d_{i j}^{c n}\right)}{d\left(c_{j}^{+}, c_{j}^{-}\right)}\right\}, \text {for } i=1,2, \cdots, 5,
$$

where $c_{j}^{+}=\max _{k}\left\{s\left(\alpha_{i j}^{(k)}, \beta_{i j}^{(k)}\right)\right\}$ and $s\left(\alpha_{i j}^{r-}, \beta_{i j}^{r-}\right) \geq s\left(\alpha_{i j}^{(k)}, \beta_{i j}^{(k)}\right) ; c_{j}^{-}=\min _{k}\left\{s\left(\alpha_{i j}^{(k)}, \beta_{i j}^{(k)}\right)\right\}$ and $s\left(\alpha_{i j}^{l-}, \beta_{i j}^{l-}\right) \leq s\left(\alpha_{i j}^{(k)}, \beta_{i j}^{(k)}\right)$ for $k=1,2, \cdots, t$. 
Table 11. Calculation results of $G U_{i}$ and $I R_{i}$

\begin{tabular}{|c|c|c|c|c|c|}
\hline & $A_{1}$ & $A_{2}$ & $A_{3}$ & $A_{4}$ & $A_{5}$ \\
\hline$G U_{i}$ & 1.1211 & 0.9195 & 0.3806 & 0.9578 & 1.3138 \\
\hline$I R_{i}$ & 0.3179 & 0.6018 & 0.1427 & 0.4519 & 0.5643 \\
\hline
\end{tabular}

Step 3. Determine the value of compromise measure $C M_{i}$ for each alternative by Eq. (41). The results are shown in Table 12.

$$
C M_{i}=\psi \frac{G U_{i}-G U^{-}}{G U^{+}-G U^{-}}+(1-\psi) \frac{I R_{i}-I R^{-}}{I R^{+}-I R^{-}}, \text {for } i=1,2, \cdots, 5,
$$

where $G U^{-}=\min _{i} G U_{i}, G U^{+}=\max _{i} G U_{i}, I R^{-}=\min _{i} I R_{i}, I R^{+}=\max _{i} I R_{i}$. The coefficient $\psi$ represents the trade-off of the $\mathrm{DM}$ regarding $G U_{i}$ and $I R_{i}$ over the conflicting criteria: if $0<\psi<0.5$, then the DM prefers to minimize the individual regret against group utility; otherwise, the DM prefers to group utility when $0.5<\psi<1$. Especially, if $\psi=0.5$, then the same attentions from the DM are paid to both the individual regret and group utility.

Table 12. Values of the compromise measure with different values of $\psi$

\begin{tabular}{|c|c|c|c|c|c|c|c|c|c|}
\hline & $\psi=0.1$ & $\psi=0.2$ & $\psi=0.3$ & $\psi=0.4$ & $\psi=0.5$ & $\psi=0.6$ & $\psi=0.7$ & $\psi=0.8$ & $\psi=0.9$ \\
\hline$C M_{1}$ & 0.4227 & 0.4640 & 0.5052 & 0.5464 & 0.5876 & 06288 & 0.6700 & 0.7112 & 0.7524 \\
\hline$C M_{2}$ & 0.9578 & 0.9155 & 0.8733 & 0.8310 & 0.7888 & 0.7465 & 0.7043 & 0.6620 & 0.6198 \\
\hline$C M_{3}$ & 0.0000 & 0.0000 & 0.0000 & 0.0000 & 0.0000 & 0.0000 & 0.0000 & 0.0000 & 0.0000 \\
\hline$C M_{4}$ & 0.6681 & 0.6626 & 0.6571 & 0.6516 & 0.6461 & 0.6406 & 0.6351 & 0.6295 & 0.6240 \\
\hline$C M_{5}$ & 0.9265 & 0.9347 & 0.9428 & 0.9510 & 0.9592 & 0.9673 & 0.9755 & 0.9837 & 0.9918 \\
\hline Order & 31452 & 31452 & 31452 & 31425 & 31425 & 31425 & 34125 & 34215 & 32415 \\
\hline
\end{tabular}

Note: "31452" in Table 11 denotes the ranks of the alternatives, meaning $A_{3} \succ A_{1} \succ A_{4} \succ A_{5} \succ A_{2}$.

Step 4. From Table 12, we obtain that the compromise solution is $A_{3}$. That is to say, $A_{3}$ is the optimal investment project.

As mentioned above, there exist several differences among the rankings of the alternatives derived by the q-ROF TOPSIS method, q-ROF VIKOR method, and q-ROF GLDS method. Using the q-ROF TOPSIS method, we have $A_{3} \succ A_{4} \succ A_{5} \succ A_{2} \succ A_{1}$. By the q-ROF VIKOR method, the ranking of the alternatives varies with the value of $\psi$ : (1) if $\psi=0.1,0.2,0.3$, then we have $A_{3} \succ A_{1} \succ A_{4} \succ A_{5} \succ A_{2}$; (2) if $\psi=0.4,0.5,0.6$, then we obtain $A_{3} \succ A_{1} \succ A_{4} \succ A_{2} \succ A_{5}$; (3) if $\psi=0.7,0.8,0.9$, the rankings of the alternatives are $A_{3} \succ A_{4} \succ A_{1} \succ A_{2} \succ A_{5}, A_{3} \succ A_{4} \succ A_{2} \succ A_{1} \succ A_{5}$ and $A_{3} \succ A_{2} \succ A_{4} \succ A_{1} \succ A_{5}$, respectively. By the q-ROF GLDS method, we derive the ranking of the alternatives as $A_{3} \succ A_{2} \succ$ $A_{4} \succ A_{1} \succ A_{5}$, which is the same as that determined by the q-ROF VIKOR method ( $\psi=0.9$ ). However, the optimal investment project is always $A_{3}$ no matter what method is used.

Note that the method to determine the positive ideal solution pis and the negative ideal solution nis is the same as NIS ${ }^{r}$ and NISl, shown in Section 3.2. As demonstrated in Section 3.2 , in actual life, there always does not exist the pis because different DMs may have distinct preferences on decision-making problems. Meanwhile, it is also hard to find the optimal so- 
lution, namely the PIS, which is accepted by all the DMs simultaneously. More importantly, the formula to calculate the values of relative coefficient is questionable (Yue, 2011). Thus, the result obtained by the q-ROF TOPSIS method is unconvincing. Like the q-ROF TOPSIS method, the approach to derive pis and nis also exists defects for the q-ROF VIKOR method. However, all above defects are tackled by the improved q-ROF GLDS method.

\subsubsection{Sensitivity analyses}

(1) Change in the weights of experts

Experts' weights play an important role in the process of solving MCDM problems (Mukhametzyanov \& Pamucar, 2018). In the following, we make a sensitivity analysis about the proposed method by changing the weights of experts (see Table 13).

Subsequently, according to Eq. (25) or Model 2, we can obtain the weight vector of criteria, which are shown in Table 14.

Figure 3 depicts the final scores of the alternatives under different experts' weights to illustrate the effect of the experts' weights on the ranking results. From Figure 3, we can obtain that when expert weight allocations are S-0, S-1, S-2, S-3 and S-4, then, the ranking results of the alternatives are the same, namely $A_{3} \succ A_{2} \succ A_{4} \succ A_{5} \succ A_{1}$; while the ranking result of the alternatives varies slightly, shown as $A_{3} \succ A_{4} \succ A_{2} \succ A_{5} \succ A_{1}$, if the expert weight allocations is S-5. It shows that the orders of alternatives 2 and 4 have been changed. Next, the mean score of each alternative under the six weight assignments can be calculated as $(-0.9168,0.1760,0.3434,0.1295,-0.1367)$, based on which, we obtain the ranking result of the alternatives as $A_{3} \succ A_{2} \succ A_{4} \succ A_{5} \succ A_{1}$. The scores of the alternatives vary with the values of experts' weights, but the optimal alternative is always $A_{3}$. Since changes in experts'

Table 13. Experts' weights assignment

\begin{tabular}{|c|c|c|c|c|c|c|}
\hline Experts & $\begin{array}{c}\text { (S-0) Under } \\
\text { the proposed } \\
\text { method }\end{array}$ & $\begin{array}{c}\text { (S-1) The } \\
\text { same weights }\end{array}$ & $\begin{array}{c}\text { (S-2) Priority } \\
\text { of Expert 1 }\end{array}$ & $\begin{array}{c}\text { (S-3) Priority } \\
\text { of Expert 2 }\end{array}$ & $\begin{array}{c}\text { (S-4) Priority } \\
\text { of Expert 3 }\end{array}$ & $\begin{array}{c}\text { (S-5) Priority } \\
\text { of Expert 4 }\end{array}$ \\
\hline$\lambda^{(1)}$ & 0.2589 & 0.25 & 0.4 & 0.2 & 0.2 & 0.2 \\
\hline$\lambda^{(2)}$ & 0.2153 & 0.25 & 0.2 & 0.4 & 0.2 & 0.2 \\
\hline$\lambda^{(3)}$ & 0.2378 & 0.25 & 0.2 & 0.2 & 0.4 & 0.2 \\
\hline$\lambda^{(4)}$ & 0.2880 & 0.25 & 0.2 & 0.2 & 0.2 & 0.4 \\
\hline
\end{tabular}

Note: The term "priority of Expert 1" means Expert 1 being with the biggest weight among all experts.

Table 14. The weights of criteria in different situations

\begin{tabular}{|c|c|c|c|c|c|c|}
\hline Criteria & $(\mathrm{S}-0)$ & $(\mathrm{S}-1)$ & $(\mathrm{S}-2)$ & $(\mathrm{S}-3)$ & $(\mathrm{S}-4)$ & $(\mathrm{S}-5)$ \\
\hline$c_{1}$ & 0.1425 & 0.1407 & 0.1299 & 0.1377 & 0.1442 & 0.1411 \\
\hline$c_{2}$ & 0.3050 & 0.3009 & 0.2885 & 0.3000 & 0.3021 & 0.3048 \\
\hline$c_{3}$ & 0.1823 & 0.1797 & 0.1759 & 0.1766 & 0.1805 & 0.1806 \\
\hline$c_{4}$ & 0.3179 & 0.3114 & 0.3064 & 0.3112 & 0.2930 & 0.3219 \\
\hline$c_{5}$ & 0.0949 & 0.1107 & 0.1013 & 0.1002 & 0.1451 & 0.1073 \\
\hline$c_{6}$ & 0.0427 & 0.0388 & 0.0392 & 0.0326 & 0.0392 & 0.0481 \\
\hline
\end{tabular}




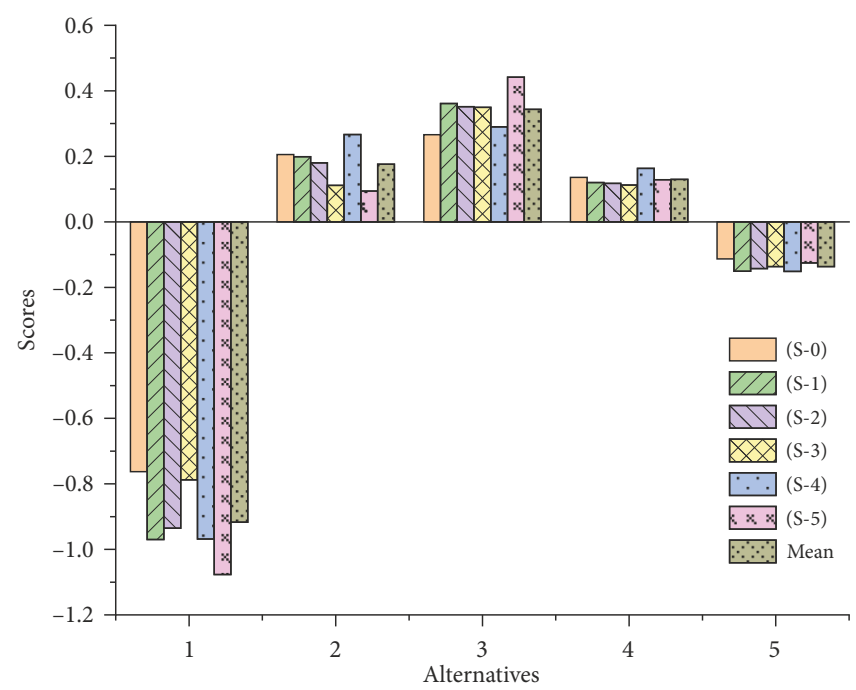

Figure 3. The final scores of alternatives under different experts' weights

weights have little impact on the ranking results of the alternatives, the proposed q-ROFGLDS method has good robustness and can be used for solving MCDM problems.

(2) Change in the weights of criteria

We further make a sensitivity analysis about the proposed method by changing the weights of criteria (Pamučar, Božanić, \& Ranđelović, 2017). The weights of the criteria are given in Table 15.

From Figure 4(a), we can obtain that: (1) when criterion weight allocation is $\mathrm{H}-1$, the ranking result of the alternatives is $A_{3} \succ A_{2} \succ A_{4} \succ A_{5} \succ A_{1}$; (2) when criterion weight allocation is $\mathrm{H}-2$, then the ranking result of the alternatives is $A_{2} \succ A_{4} \succ A_{5} \succ A_{3} \succ A_{1}$; (3) when criterion weight allocation is $\mathrm{H}-3, \mathrm{H}-4$ or $\mathrm{H}-5$, the ranking result of the alternatives is $A_{3} \succ A_{4} \succ A_{2} \succ A_{5} \succ A_{1}$; (4) when criterion weight allocation is $\mathrm{H}-6$, then the ranking result of the alternative is $A_{4} \succ A_{2} \succ A_{3} \succ A_{1} \succ A_{5}$; (5) when criterion weight allocation is H-7, then the ranking result of the alternative is $A_{4} \succ A_{3} \succ A_{2} \succ A_{1} \succ A_{5}$. The above-mentioned results show that the changes in the weights of criteria have obviously impact on the ranking results of alternatives regarding the q-ROF TOPSIS method.

Table 15. Criteria’s weights assignment

\begin{tabular}{|l|c|c|c|c|c|c|}
\hline \multicolumn{1}{|c|}{ Situations } & $c_{1}$ & $c_{2}$ & $c_{3}$ & $c_{4}$ & $c_{5}$ & $c_{6}$ \\
\hline (H-1) Approximately equal weight Criteria & 0.17 & 0.17 & 0.17 & 0.17 & 0.16 & 0.16 \\
\hline (H-2) Priority of $c_{1}$ & 0.30 & 0.14 & 0.14 & 0.14 & 0.14 & 0.14 \\
\hline (H-3) Priority of $c_{2}$ & 0.14 & 0.30 & 0.14 & 0.14 & 0.14 & 0.14 \\
\hline$(\mathrm{H}-4)$ Priority of $c_{3}$ & 0.14 & 0.14 & 0.30 & 0.14 & 0.14 & 0.14 \\
\hline$(\mathrm{H}-5)$ Priority of $c_{4}$ & 0.14 & 0.14 & 0.14 & 0.30 & 0.14 & 0.14 \\
\hline$(\mathrm{H}-6)$ Priority of $c_{5}$ & 0.14 & 0.14 & 0.14 & 0.14 & 0.30 & 0.14 \\
\hline$(\mathrm{H}-7)$ Priority of $c_{6}$ & 0.14 & 0.14 & 0.14 & 0.14 & 0.14 & 0.30 \\
\hline
\end{tabular}


a)
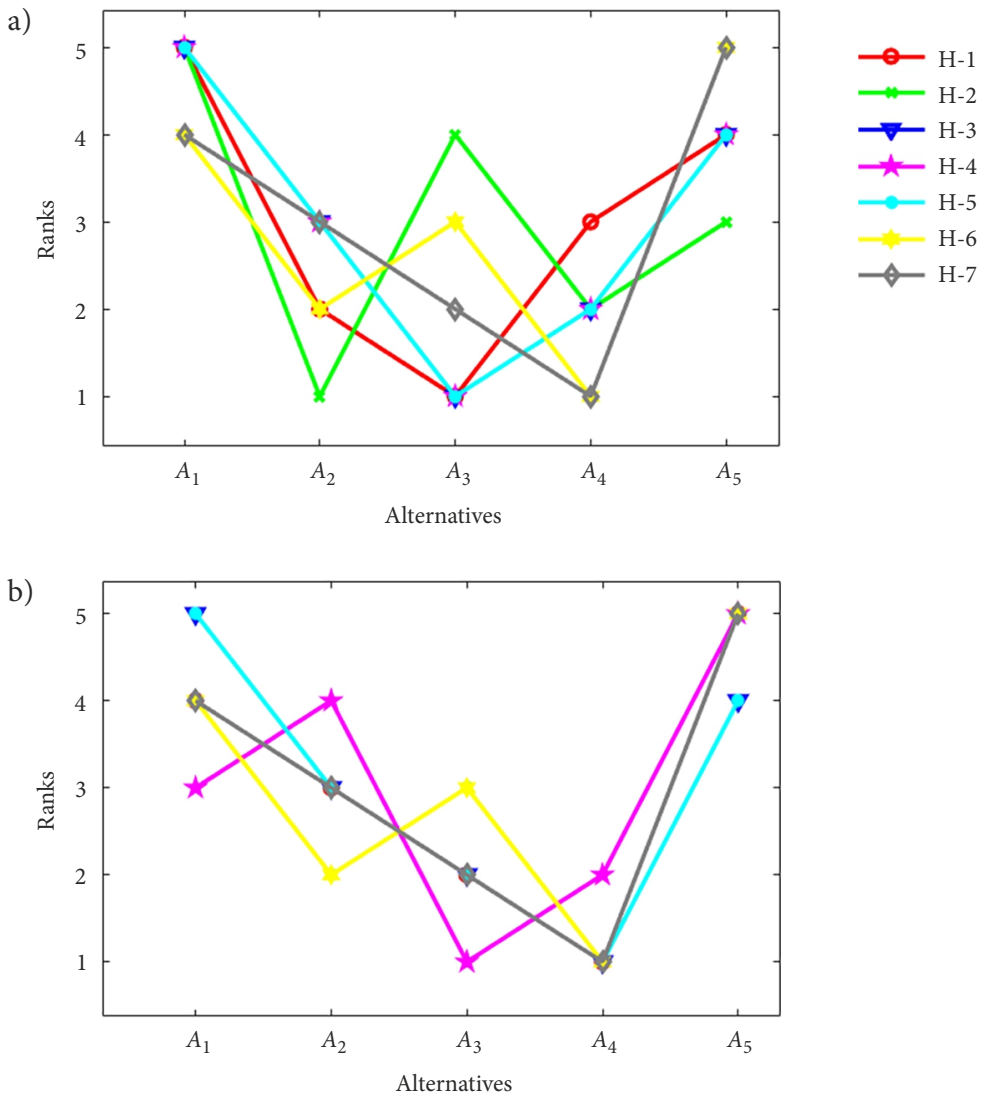

Figure 4. Ranking schematic map under different weight distribution: $\mathrm{a}$ - sensitive analyses of q-R-TOPSIS; $\mathrm{b}$ - sensitive analyses of q-R-GLDS

Next, using the proposed q-ROF GLDS method, we can obtain that: (1) when criterion weight allocation is $\mathrm{H}-1, \mathrm{H}-2$ or $\mathrm{H}-7$, then the ranking result of the alternatives is $A_{4} \succ A_{3} \succ A_{2} \succ A_{1} \succ A_{5}$; (2) when criterion weight allocation is $\mathrm{H}-3$ or $\mathrm{H}-5$, then the ranking result of the alternatives is $A_{4} \succ A_{3} \succ A_{2} \succ A_{5} \succ A_{1}$; (3) when criterion weight allocations is $\mathrm{H}-4$, then the ranking result of the alternatives is $A_{3} \succ A_{4} \succ A_{1} \succ A_{2} \succ A_{5}$; (4) when criterion weight allocation is $\mathrm{H}-6$, then the ranking result of the alternatives is $A_{4} \succ A_{2} \succ A_{3} \succ A_{1} \succ A_{5}$.

Figure 4 shows that $A_{3}$ is a highly volatile scheme under different weight assignments of criteria. $A_{3}$ ranks first four times in seven experiments under the q-ROF-TOPSIS method; while $A_{4}$ ranked first six times in seven experiments under the proposed q-ROF GLDS method. It shows that the optimal scheme selected by the q-ROF GLDS method is less affected by the change of criteria's weights. Meanwhile, for the proposed q-ROF GLDS method, changes in the weights of criteria have little impact on the ranking results of alternatives. Thus, it has a better robustness than the q-ROF TOPSIS method. In other words, the obtained optimal scheme for this case by our proposed method is $A_{3}$, the same as the result of $\mathrm{H}-2$. It shows 
that there are obvious differences among the five schemes under the third criterion and product innovation does play a key role in future earnings for angle capital.

As has been mentioned above, the proposed q-ROF GLDS method has the following advantages:

- Methods to determine the weight vectors of DMs and criteria are respectively considered in the method. It would eliminate the influence of subjective factors as much as possible.

- Both the dominance flow and order scores of alternatives are considered in the method. In this regard, the solution obtained by the q-ROF GLDS method is not only the closest one to the ideal solution but also dominates others.

\section{Conclusions}

In this paper, based on the original GLDS method, we proposed an MCDM method to tackle the problems with q-ROFS information. Firstly, we defined a new distance measure of q-ROFNs in which all the membership degrees, non-membership degrees and hesitancy degrees were considered at the same time. Thus, it can measure the deviations among q-ROFNs more accurately than existing formulas. Subsequently, using the improved TOPSIS method and the maximum deviation method, two methods to determine the weights of DMs and criteria were investigated in detail. On this basis, we improved the original GLDS method by integrating the order scores of alternatives and the proposed weight-determining methods. Finally, the proposed MCDM method was demonstrated by a case study regarding the investment evaluation of $\mathrm{BE}$ angle capital. Comparative and sensitive analyses were provided to demonstrate the robustness and efficiency of the proposed method.

In the future, we will apply the proposed q-ROF GLDS method to deal with other problems, such as hospital management, supplier selection and education evaluation. In addition, the application of the proposed method under the interval-valued q-ROFS environment is also an interesting direction to be studied.

\section{Funding}

The work was supported by the National Natural Science Foundation of China under Grant 71571156, the 2019 Sichuan Planning Project of Social Science (No. SC18A007), and the 2019 Soft Science Project of Sichuan Science and Technology Department (No. 2019JDR0141).

\section{Author contributions}

Huchang LIAO and Hongrui ZHANG conceived the study and were responsible for the design and development of the data analysis. Hongrun ZHANG, Cheng ZHANG and Xingli WU were responsible for data collection and analysis. Cheng ZHANG were responsible for data interpretation. Huchang LIAO, Hongrun ZHNG and Abbas MARDANI wrote the first draft of the article. Abdullah AL-BARAKATI checked the revised version of the paper. 


\section{Disclosure statement}

The authors have no competing financial, professional, or personal interests from other parties that are related to this paper.

\section{References}

Atanassov, K. (1986). Intuitionistic fuzzy sets. Fuzzy Sets and Systems, 20, 87-96. https://doi.org/10.1007/978-3-7908-1870-3_1

Du, W. S. (2018a). Minkowski-type distance measures for generalized orthopair fuzzy sets. International Journal of Intelligent Systems, 3, 802-817. https://doi.org/10.1002/int.21968

$\mathrm{Du}, \mathrm{W}$. S. (2018b). Correlation and correlation coefficient of generalized orthopair fuzzy sets. International Journal of Intelligent Systems, 34(4), 564-583. https://doi.org/10.1002/int.22065

Fu, Z. G., Wu, X. L., Liao, H. C., \& Herrera, F. (2018). Underground mining method selection with the hesitant fuzzy linguistic gained and lost dominance score method. IEEE Access, 6(1), 66442-66458. https://doi.org/10.1109/access.2018.2878784

Gao, J., Liang, Z. L., Shang, J., \& Xu, Z. S. (2018). Continuities, derivatives and differentials of q-rung orthopair fuzzy functions. IEEE Transactions on Fuzzy Systems, 27(8), 1687-1699. https://doi.org/10.1109/tfuzz.2018.2887187

Joshi, B. P., Singh, A., Bhatt, P. K., \& Vaisla, K. S. (2018). Interval valued q-rung orthopair fuzzy sets and their properties. Journal of Intelligent and Fuzzy Systems, 35(5), 5225-5230. https://doi.org/10.3233/jifs-169806

Kahneman, D., \& Tversky, A. (2013). Prospect theory: An analysis of decision under risk. In Handbook of the fundamentals of financial decision making (part I, pp. 99-127). World Scientific. https://doi.org/10.1142/9789814417358_0006

Li, D. Q., \& Zeng, W. Y. (2018). Distance measure of Pythagorean fuzzy sets. International Journal of Intelligent Systems, 33, 348-361. https://doi.org/10.1002/int.21934

Liao, H. C., Jiang, L. S., Xu, Z. S., Xu, J. P., \& Herrera, F. (2017). A linear programming method for multiple criteria decision making with probabilistic linguistic information. Information Sciences, 415-416, 341-355. https://doi.org/10.1016/j.ins.2017.06.035

Liao, H. C., Wu, D., Huang, Y. L., Ren, P. J., Xu, Z. S., \& Verma, M. (2018a). Green logistic provider selection with a hesitant fuzzy linguistic thermodynamic method integrating prospect theory and PROMETHEE. Sustainability, 10(4), 1291. https://doi.org/10.3390/su10041291

Liao, H. C., Xu, Z. S., Herrera-Viedma, E., \& Herrera, F. (2018b). Hesitant fuzzy linguistic term set and its application in decision making: A state-of-the art survey. International Journal of Fuzzy Systems, 20(7), 2084-2110. https://doi.org/10.1007/s40815-017-0432-9

Liu, F., Aiwu, G., Lukovac, V., \& Vukic, M. (2018a). A multicriteria model for the selection of the transport service provider: A single valued neutrosophic DEMATEL multicriteria model. Decision Making: Application in Management and Engineering, 1(2), 121-130. https://doi.org/10.31181/dmame18021281

Liu, P. D., Chen, X. M., \& Wang, P. (2018b). Multiple-attribute group decision-making based on q-rung orthopair fuzzy power Maclaurin symmetric mean operators. IEEE Transactions on Fuzzy Systems, 1-16. https://doi.org/10.1109/TSMC.2018.2852948

Liu, W. S., \& Liao, H. C. (2017). A bibliometric analysis of fuzzy decision research during 1970-2015. International Journal of Fuzzy Systems, 19(1), 1-14. https://doi.org/10.1007/s40815-016-0272-Z 
Liu, P. D., \& Liu, J. L. (2018). Some q-rung orthopair fuzzy Bonferroni mean operators and their application to multi-attribute group decision making. International Journal of Intelligent Systems, 33(2), 315-347. https://doi.org/10.1002/int.21933

Liu, P. D., \& Wang, P. (2018). Some q-rung orthopair fuzzy aggregation operators and their applications to multiple-attribute decision making. International Journal of Intelligent Systems, 33(2), 259-280. https://doi.org/10.1002/int.21927

Liu, P. D., \& Wang, P. (2019). Multiple-attribute decision making based on Archimedean Bonferroni operators of q-rung orthopair fuzzy numbers. IEEE Transactions on Fuzzy Systems, 27(5), 834-848. https://doi.org/10.1109/TFUZZ.2018.2826452

Mukhametzyanov, I., \& Pamucar, D. (2018). A sensitivity analysis in MCDM problems: A statistical approach. Decision Making: Applications in Management and Engineering, 1(2), 51-80. https://doi.org/10.31181/dmame1802050m

Pamučar, D., Badi, I., Sanja, K., \& Obradović, R. (2018). A novel approach for the selection of powergeneration technology using a linguistic neutrosophic CODAS method: A case study in Libya. Energies, 11(9), 2489. https://doi.org/10.3390/en11092489

Pamučar, D., Božanić, D., \& Ranđelović, A. (2017). Multi-criteria decision making: An example of sensitivity analysis. Serbian Journal of Management, 12(1), 1-27. http://doi.org/10.5937/sjm12-9464

Pamučar, D., Sremac, S., Stević, Ž., Ćirović, G., \& Tomić, D. (2019). New multi-criteria LNN WASPAS model for evaluating the work of advisors in the transport of hazardous goods. Neural Computing and Applications, 31(9), 5045-5068. https://doi.org/10.1007/s00521-018-03997-7

Peng, X. D., Dai, J. G., \& Garg, H. (2018). Exponential operation and aggregation operator for q-rung orthopair fuzzy set and their decision-making method with a new score function. International Journal of Intelligent Systems, 33, 2255-2282. https://doi.org/10.1002/int.22028

Szmidt, E., \& Kacprzyk, J. (2000). Distances between intuitionistic fuzzy sets. Fuzzy Sets and Systems, 114, 505-518. https://doi.org/10.1016/s0165-0114(98)00244-9

Wang, Y. M. (1997). Using the method of maximizing deviations to make decision for multi-indices. Journal of System Engineering and Electronics, 8(3), 21-26. Retrieved from https://ieeexplore.ieee. org/abstract/document/6079108

Wang, J., Zhang, R. T., Zhu, X. M., Zhou, Z., Shang, X. P., \& Li, W. Z. (2019). Some q-rung orthopair fuzzy Muirhead means with their application to multi-attribute group decision making. Journal of Intelligent and Fuzzy Systems, 36(2), 1599-1614. https://doi.org/10.3233/JIFS-18607

Wei, G. W., Gao, H., \& Wei, Y. (2018). Some q-rung orthopair fuzzy Heronian mean operators in multiple attribute decision making. International Journal of Intelligent Systems, 33, 1426-1458. https://doi.org/10.1002/int.21927

Wu, X. L., \& Liao, H. C. (2019). A consensus-based probabilistic linguistic gained and lost dominance score method. European Journal of Operational Research, 272(3), 1017-1027. https://doi.org/10.1016/j.ejor.2018.07.044

Yager, R. R. (2014). Pythagorean membership grades in multicriteria decision making. IEEE Transactions on Fuzzy Systems, 22, 958-965. https://doi.org/10.1109/tfuzz.2013.2278989

Yager, R. R. (2017). Generalized orthopair fuzzy sets. IEEE Transactions on Fuzzy Systems, 25, 12221230. https://doi.org/10.1109/tfuzz.2016.2604005

Yue, Z. L. (2011). A method for group decision-making based on determining weights of decision makers using TOPSIS. Applied Mathematical Modelling, 35, 1926-1936. https://doi.org/10.1016/j.apm.2010.11.001

Zadeh, L. A. (1965). Fuzzy sets. Information and Control, 8(3), 338-353. https://doi.org/10.1016/S0019-9958(65)90241-X 
Zhang, X. L., \& Xu, Z. S. (2014). Extension of TOPSIS to multiple criteria decision making with Pythagorean fuzzy sets. International Journal of Intelligent Systems, 29, 1061-1078. https://doi.org/10.1002/int.21676

Zhang, Y. X., Xu, Z. S., \& Liao, H. C. (2019). Water security evaluation based on the TODIM method with probabilistic linguistic terms set. Soft Computing, 23(15), 6215-6230.

https://doi.org/10.1007/s00500-018-3276-9

\section{APPENDIX}

\section{The proof of Theorem 1}

(1) It is easy to obtain that $d\left(a_{1}, a_{2}\right)=d\left(a_{2}, a_{1}\right)$, and therefore the proof is omitted.

(2) Case 1.

$d\left(a_{1}, a_{2}\right)=\frac{\left|q_{2}-q_{1}\right|+1}{q_{*}} \cdot \sqrt{\frac{1}{2}\left(\left(\left(\alpha_{1}\right)^{q_{1}}-\left(\alpha_{2}\right)^{q_{2}}\right)^{2}+\left(\left(\beta_{1}\right)^{q_{1}}-\left(\beta_{2}\right)^{q_{2}}\right)^{2}+\left(\left(\gamma_{1}\right)^{q_{1}}-\left(\gamma_{2}\right)^{q_{2}}\right)^{2}\right)}$.

If

$d\left(a_{1}, a_{2}\right)=\frac{\left|q_{2}-q_{1}\right|+1}{q_{*}} \cdot \sqrt{\frac{1}{2}\left(\left(\left(\alpha_{1}\right)^{q_{1}}-\left(\alpha_{2}\right)^{q_{2}}\right)^{2}+\left(\left(\beta_{1}\right)^{q_{1}}-\left(\beta_{2}\right)^{q_{2}}\right)^{2}+\left(\left(\gamma_{1}\right)^{q_{1}}-\left(\gamma_{2}\right)^{q_{2}}\right)^{2}\right)}=0$,

then we have $\left(\alpha_{1}\right)^{q_{1}}=\left(\alpha_{2}\right)^{q_{2}},\left(\beta_{1}\right)^{q_{1}}=\left(\beta_{2}\right)^{q_{2}}$ and $\left(\gamma_{1}\right)^{q_{1}}=\left(\gamma_{2}\right)^{q_{2}}$. According to the definition of q-ROFN (Liu \& Wang, 2018), we have

$d\left(a_{1}, a_{2}\right)=\frac{1}{q_{*}} \cdot \sqrt{\frac{1}{2}\left(\left(\left(\alpha_{1}\right)^{q_{*}}-\left(\alpha_{2}\right)^{q_{*}}\right)^{2}+\left(\left(\beta_{1}\right)^{q_{*}}-\left(\beta_{2}\right)^{q_{*}}\right)^{2}+\left(\left(\gamma_{1}\right)^{q_{*}}-\left(\gamma_{2}\right)^{q_{*}}\right)^{2}\right)}$

holds if $\left(\alpha_{1}\right)^{q_{1}}=\left(\alpha_{2}\right)^{q_{2}},\left(\beta_{1}\right)^{q_{1}}=\left(\beta_{2}\right)^{q_{2}}$ and $q_{1} \neq q_{2}$. Thus, for Situation $1, q_{1}=q_{2}$ holds. It follows that $a_{1}=a_{2}$.

In addition, if $a_{1}=a_{2}$ holds, it is easy to obtain that $d\left(a_{1}, a_{2}\right)=0$.

Case 2. $d\left(a_{1}, a_{2}\right)=\frac{1}{q_{*}} \cdot \sqrt{\frac{1}{2}\left(\left(\left(\alpha_{1}\right)^{q_{*}}-\left(\alpha_{2}\right)^{q_{*}}\right)^{2}+\left(\left(\beta_{1}\right)^{q_{*}}-\left(\beta_{2}\right)^{q_{*}}\right)^{2}+\left(\left(\gamma_{1}\right)^{q_{*}}-\left(\gamma_{2}\right)^{q_{*}}\right)^{2}\right)}$, if $\left(\alpha_{1}\right)^{q_{1}}=\left(\alpha_{2}\right)^{q_{2}},\left(\beta_{1}\right)^{q_{1}}=\left(\beta_{2}\right)^{q_{2}}$ and $q_{1} \neq q_{2}$.

$$
\text { If } d\left(a_{1}, a_{2}\right)=\frac{1}{q_{*}} \cdot \sqrt{\frac{1}{2}\left(\left(\left(\alpha_{1}\right)^{q_{*}}-\left(\alpha_{2}\right)^{q_{*}}\right)^{2}+\left(\left(\beta_{1}\right)^{q_{*}}-\left(\beta_{2}\right)^{q_{*}}\right)^{2}+\left(\left(\gamma_{1}\right)^{q_{*}}-\left(\gamma_{2}\right)^{q_{*}}\right)^{2}\right)}=0 \text {, }
$$

then we have $\left(\alpha_{1}\right)^{q_{*}}=\left(\alpha_{2}\right)^{q_{*}},\left(\beta_{1}\right)^{q_{*}}=\left(\beta_{2}\right)^{q_{*}}$ and $\left(\gamma_{1}\right)^{q_{*}}=\left(\gamma_{2}\right)^{q_{*}}$. It follows that $a_{1}=a_{2}$.

If $a_{1}=a_{2}$ holds, we have

$$
d\left(a_{1}, a_{2}\right)=\frac{\left|q_{2}-q_{1}\right|+1}{q_{*}} \cdot \sqrt{\frac{1}{2}\left(\left(\left(\alpha_{1}\right)^{q_{1}}-\left(\alpha_{2}\right)^{q_{2}}\right)^{2}+\left(\left(\beta_{1}\right)^{q_{1}}-\left(\beta_{2}\right)^{q_{2}}\right)^{2}+\left(\left(\gamma_{1}\right)^{q_{1}}-\left(\gamma_{2}\right)^{q_{2}}\right)^{2}\right)}=0 .
$$


As analyzed above, we prove the property that $d\left(a_{1}, a_{2}\right)=0$ if and only if $a_{1}=a_{2}$.

(3) Case 1.

$$
d\left(a_{1}, a_{2}\right)=\frac{\left|q_{2}-q_{1}\right|+1}{q_{*}} \cdot \sqrt{\frac{1}{2}\left(\left(\left(\alpha_{1}\right)^{q_{1}}-\left(\alpha_{2}\right)^{q_{2}}\right)^{2}+\left(\left(\beta_{1}\right)^{q_{1}}-\left(\beta_{2}\right)^{q_{2}}\right)^{2}+\left(\left(\gamma_{1}\right)^{q_{1}}-\left(\gamma_{2}\right)^{q_{2}}\right)^{2}\right)} .
$$

Since $0 \leq \alpha_{1}, \beta_{1}, \gamma_{1} \leq 1 \quad\left(0 \leq \alpha_{2}, \beta_{2}, \gamma_{2} \leq 1\right)$ and $q_{1}, q_{2}$ are two integers with condition $q_{1}, q_{2} \in[1,+\infty)$, then $0 \leq\left(\alpha_{1}\right)^{q_{1}},\left(\beta_{1}\right)^{q_{1}},\left(\gamma_{1}\right)^{q_{1}} \leq 1 \quad\left(0 \leq\left(\alpha_{2}\right)^{q_{2}},\left(\beta_{2}\right)^{q_{2}},\left(\gamma_{2}\right)^{q_{2}} \leq 1\right)$ holds. It follows that $0 \leq\left(\left(\alpha_{1}\right)^{q_{1}}-\left(\alpha_{2}\right)^{q_{2}}\right)^{2},\left(\left(\beta_{1}\right)^{q_{1}}-\left(\beta_{2}\right)^{q_{2}}\right)^{2},\left(\left(\gamma_{1}\right)^{q_{1}}-\left(\gamma_{2}\right)^{q_{2}}\right)^{2} \leq 1$. Thus, we have

$$
\begin{aligned}
d\left(a_{1}, a_{2}\right) & =\frac{\left|q_{2}-q_{1}\right|+1}{q_{*}} \cdot \sqrt{\frac{1}{2}\left(\left(\left(\alpha_{1}\right)^{q_{1}}-\left(\alpha_{2}\right)^{q_{2}}\right)^{2}+\left(\left(\beta_{1}\right)^{q_{1}}-\left(\beta_{2}\right)^{q_{2}}\right)^{2}+\left(\left(\gamma_{1}\right)^{q_{1}}-\left(\gamma_{2}\right)^{q_{2}}\right)^{2}\right)} \\
& =\frac{\left|q_{2}-q_{1}\right|+1}{q_{*}} \cdot \sqrt{\frac{1}{2}\left(\left(\left(\alpha_{1}\right)^{q_{1}}-\left(\alpha_{2}\right)^{q_{2}}\right)^{2}+\left(\left(\beta_{1}\right)^{q_{1}}-\left(\beta_{2}\right)^{q_{2}}\right)^{2}+\left(\left(\alpha_{2}\right)^{q_{2}}-\left(\alpha_{1}\right)^{q_{1}}+\left(\beta_{2}\right)^{q_{2}}-\left(\beta_{1}\right)^{q_{1}}\right)^{2}\right)} \\
& \leq \frac{\left|q_{2}-q_{1}\right|+1}{q_{*}} \cdot \sqrt{\left.\frac{1}{2}\left(\left(\alpha_{1}\right)^{q_{1}}\right)^{2}+\left(\left(\beta_{1}\right)^{q_{1}}\right)^{2}+\left(\left(\alpha_{2}\right)^{q_{2}}+\left(\beta_{2}\right)^{q_{2}}\right)^{2}\right)} \\
& \leq \frac{\left|q_{2}-q_{1}\right|+1}{q_{*}} \cdot \sqrt{\frac{1}{2}(1+1)} \leq 1 .
\end{aligned}
$$

Moreover, it is easy to obtain that $d\left(a_{1}, a_{2}\right) \geq 0$. Thus, we have $0 \leq d\left(a_{1}, a_{2}\right) \leq 1$.

Case 2. $d\left(a_{1}, a_{2}\right)=\frac{1}{q_{*}} \cdot \sqrt{\frac{1}{2}\left(\left(\left(\alpha_{1}\right)^{q_{*}}-\left(\alpha_{2}\right)^{q_{*}}\right)^{2}+\left(\left(\beta_{1}\right)^{q_{*}}-\left(\beta_{2}\right)^{q_{*}}\right)^{2}+\left(\left(\gamma_{1}\right)^{q_{*}}-\left(\gamma_{2}\right)^{q_{*}}\right)^{2}\right)}$, if $\left(\alpha_{1}\right)^{q_{1}}=\left(\alpha_{2}\right)^{q_{2}},\left(\beta_{1}\right)^{q_{1}}=\left(\beta_{2}\right)^{q_{2}}$ and $q_{1} \neq q_{2}$.

Similar to Situation 1 , we have $d\left(a_{1}, a_{2}\right) \geq 0$ and

$$
\begin{aligned}
d\left(a_{1}, a_{2}\right) & =\frac{1}{q_{*}} \cdot \sqrt{\left.\frac{1}{2}\left(\left(\alpha_{1}\right)^{q_{*}}-\left(\alpha_{2}\right)^{q_{*}}\right)^{2}+\left(\left(\beta_{1}\right)^{q_{*}}-\left(\beta_{2}\right)^{q_{*}}\right)^{2}+\left(\left(\gamma_{1}\right)^{q_{*}}-\left(\gamma_{2}\right)^{q_{*}}\right)^{2}\right)} \\
& =\frac{1}{q_{*}} \cdot \sqrt{\frac{1}{2}\left(\left(\left(\alpha_{1}\right)^{q_{*}}-\left(\alpha_{2}\right)^{q_{*}}\right)^{2}+\left(\left(\beta_{1}\right)^{q_{*}}-\left(\beta_{2}\right)^{q_{*}}\right)^{2}+\left(\left(\alpha_{2}\right)^{q_{*}}-\left(\alpha_{1}\right)^{q_{*}}+\left(\beta_{2}\right)^{q_{*}}-\left(\beta_{1}\right)^{q_{*}}\right)^{2}\right)} \\
& \leq \frac{1}{q_{*}} \cdot \sqrt{\left.\frac{1}{2}\left(\left(\alpha_{1}\right)^{q_{*}}\right)^{2}+\left(\left(\beta_{1}\right)^{q_{*}}\right)^{2}+\left(\left(\alpha_{2}\right)^{q_{*}}+\left(\beta_{2}\right)^{q_{*}}\right)^{2}\right)} \\
& \leq \frac{1}{q_{*}} \cdot \sqrt{\frac{1}{2}(1+1)} \leq 1 .
\end{aligned}
$$

Thus, for Eq. (33), $0 \leq d\left(a_{1}, a_{2}\right) \leq 1$ always holds. 
(4) If $a_{1} \leq a_{2} \leq a_{3}$ and $q_{1}=q_{2}=q_{3}$, we have $\alpha_{1} \leq \alpha_{2} \leq \alpha_{3}$ and $\beta_{1} \geq \beta_{2} \geq \beta_{3}$. Then,

$$
\begin{aligned}
\left(\left(\alpha_{1}\right)^{q_{1}}-\left(\alpha_{2}\right)^{q_{2}}\right)^{2} & \leq\left(\left(\alpha_{1}\right)^{q_{1}}-\left(\alpha_{3}\right)^{q_{3}}\right)^{2},\left(\left(\beta_{1}\right)^{q_{1}}-\left(\beta_{2}\right)^{q_{2}}\right)^{2} \leq\left(\left(\beta_{1}\right)^{q_{1}}-\left(\beta_{3}\right)^{q_{3}}\right)^{2} \\
\left(\left(\gamma_{1}\right)^{q_{1}}-\left(\gamma_{2}\right)^{q_{2}}\right)^{2} & =\left(1-\left(\alpha_{1}\right)^{q_{1}}-\left(\beta_{1}\right)^{q_{1}}-\left(1-\left(\alpha_{2}\right)^{q_{2}}-\left(\beta_{2}\right)^{q_{2}}\right)\right)^{2} \\
& =\left(\left(\alpha_{2}\right)^{q_{2}}-\left(\alpha_{1}\right)^{q_{1}}+\left(\left(\beta_{2}\right)^{q_{2}}-\left(\beta_{1}\right)^{q_{1}}\right)\right)^{2} \\
& \leq\left(1-\left(\alpha_{1}\right)^{q_{1}}-\left(\beta_{1}\right)^{q_{1}}-\left(1-\left(\alpha_{3}\right)^{q_{3}}-\left(\beta_{3}\right)^{q_{3}}\right)\right)^{2} \\
& =\left(\left(\alpha_{3}\right)^{q_{3}}-\left(\alpha_{1}\right)^{q_{1}}+\left(\left(\beta_{3}\right)^{q_{3}}-\left(\beta_{1}\right)^{q_{1}}\right)\right)^{2} \\
& =\left(\left(\gamma_{1}\right)^{q_{1}}-\left(\gamma_{3}\right)^{q_{3}}\right)^{2} .
\end{aligned}
$$

Thus,

$$
\begin{aligned}
& d\left(a_{1}, a_{2}\right)= \\
& =\frac{\left|q_{2}-q_{1}\right|+1}{q_{*}} \cdot \sqrt{\frac{1}{2}\left(\left(\left(\alpha_{1}\right)^{q_{1}}-\left(\alpha_{2}\right)^{q_{2}}\right)^{2}+\left(\left(\beta_{1}\right)^{q_{1}}-\left(\beta_{2}\right)^{q_{2}}\right)^{2}+\left(\left(\gamma_{1}\right)^{q_{1}}-\left(\gamma_{2}\right)^{q_{2}}\right)^{2}\right)} \\
& \leq \frac{\left|q_{3}-q_{1}\right|+1}{q_{*}} \cdot \sqrt{\frac{1}{2}\left(\left(\left(\alpha_{1}\right)^{q_{1}}-\left(\alpha_{3}\right)^{q_{3}}\right)^{2}+\left(\left(\beta_{1}\right)^{q_{1}}-\left(\beta_{3}\right)^{q_{3}}\right)^{2}+\left(\left(\gamma_{1}\right)^{q_{1}}-\left(\gamma_{3}\right)^{q_{3}}\right)^{2}\right)}=d\left(a_{1}, a_{3}\right) .
\end{aligned}
$$

In the same way, we can prove $d\left(a_{2}, a_{3}\right) \leq d\left(a_{1}, a_{3}\right)$, which completes the proof of Theorem 1 . 